\title{
Robust human development rankings
}

\author{
Laurens Cherchye • Erwin Ooghe • \\ Tom Van Puyenbroeck
}

Received: 23 January 2006 / Accepted: 23 March 2007

(C) Springer Science + Business Media B.V. 2007

\begin{abstract}
The United Nations' Human Development Index (HDI) considers scores in three dimensions - income, school enrolment and literacy rate, longevity - and combines them into a single figure that measures the degree of development of a given country. However, there is disagreement about (1) how to weight the scores in the different dimensions and (2) how to aggregate the weighted scores over the different dimensions. At the risk of stressing the obvious, changes in weighting and/or aggregation will affect the country rankings. First, we focus on robust rankings, i.e., rankings which hold for a wide set of weighting and/or aggregation procedures. Second, we show that all proposed ranking procedures can be implemented via linear programming techniques. Third, we illustrate how our methodology can prove useful in assessing the robustness of the human development country ranking/classification (produced annually by the United Nations) in a descriptive and statistical way.
\end{abstract}

Keywords Human development index • Lorenz dominance • Linear programming • Robustness analysis

JEL Classification $\mathrm{C} 61 \cdot \mathrm{D} 63 \cdot \mathrm{I} 31 \cdot \mathrm{O} 10$

L. Cherchye

Center for Economic Studies, Katholieke Universiteit Leuven Campus Kortrijk,

E. Sabbelaan 53, 8500 Kortrijk, Belgium

e-mail: laurens.cherchye@kulak.be

E. Ooghe $(\varangle) \cdot$ T. Van Puyenbroeck

Center for Economic Studies, Katholieke Universiteit Leuven,

Naamsestraat 69, 3000 Leuven, Belgium

e-mail: erwin.ooghe@econ.kuleuven.be

T. Van Puyenbroeck

European University College Brussels (Ehsal),

Stormstraat 2, 1000 Brussels, Belgium

e-mail: tom.vanpuyenbroeck@ehsal.be 
"It is better to be vaguely right, than precisely wrong." (Wildon Carr)

\section{Introduction}

Gauging human development is a much needed, yet very challenging and intricate enterprise. The epitome of this endeavour is the series of Human Development Reports (HDRs) commissioned by the United Nations Development Programme (UNDP) since 1990. Ever since their inception, these reports have stressed that human development cannot be assessed by looking at income alone, e.g., by analyzing the evolution of a country's GDP per capita over time. Upholding the view that "people are the real wealth of nations" ([23], p. 217), this measure can indeed hardly be regarded as an end in itself. Heavily influenced by the work of Amartya Sen, the HDRs have instead continuously endorsed the idea that people's 'capabilities' are the prime objectives of human development. Specifically, this means that human development ought to be regarded as a process of expanding peoples' choices, i.e., of taking away obstacles to the things a person could do and be in his/her life. Thus income continues to be an important yardstick - since it is indicative of a person's "command over resources" (Anand and Sen [1]) - but has been complemented by numerous other indicators. In fact, the typical HDR is composed of dozens of tables and figures, reporting on hundreds of indicators that are all related in some way or another to the overarching concept of human development.

Unfortunately, a plethora of statistics is ill-suited as a tool for public communication. Grabbing the attention of various stakeholders and triggering public debate are major reasons for the fact that, since the beginning, the reports have also provided a summary 'Human Development Index' (HDI). This index singles out (a) leading a long and healthy life, (b) being knowledgeable, and (c) enjoying a decent standard of living as three key aspects of human development. The index surely succeeds in attracting public interest to the HDR's, as witnessed by the media coverage that accompanies the release of a new HDR. In point of fact, the media headlines quite often relate to the country ranking that results from the HDI.

Evidently, by its very nature a summary index is bound to conceal important aspects of a complex phenomenon such as human development. The HDI's authors are actually the first to stress that the index is by no means a complete measure of a country's level of development. ${ }^{1}$ In fact, the authors have always been very meticulous in spelling out their methodology, in making the underlying data accessible, and in fostering the transparency of the HDI's construction by including interactive "Do It Yourself"-versions on their official website (hdr.undp.org/statistics/indices). As a result, we will not give a detailed explanation of its construction here. It will suffice to point at the three steps that lead up to the HDI. First, each of the three aforementioned dimensions is associated with particular quantitative figures (viz. life expectancy at birth; adult literacy rate and the school enrolment ratio; GDP per capita as measured in PPP US\$). In their original form these individual figures are incommensurable. Therefore, the original data are normalized, i.e., reexpressed to make them comparable across dimensions: the HDI normalizes the raw

\footnotetext{
${ }^{1}$ As a matter of fact, this statement can be found as such on hdr.undp.org/statistics/faq/.

空 Springer
} 
data figures into a score on a scale from 0 to 1 . Once this has been accomplished, the scores are weighted in a second step according to the relative importance one wants to attach to the different dimensions: the HDI weights the scores in each dimension equally. Finally, in a third step, the weighted scores are aggregated via an index: the HDI takes the sum of the (equally) weighted scores. Even this briefest of accounts illustrates that the HDI indeed errs on the side of simplicity: methodological transparency and substantive precision are not exactly synonymous. ${ }^{2}$

Now, precisely in view of the fact that the HDI is scrupulously presented as only a part of the overall picture, attacking its method of construction seems a rather easy criticism. It may lead one to wonder why so many researchers make every effort to analyze, criticize and try to improve that construction methodology. We think at least two reasons can be given. First, the HDR's authors have proven to be receptive to such criticisms; its construction has been slightly modified over the years and these modifications have at least partially been inspired by critical annotations from the scientific community (see, e.g., Fukada-Parr [10], Fukada-Parr and Shiva Kumar [11]). Second, and more importantly, precisely because the HDI has such a high media profile, it seems to have acquired a similarly eye-catching 'test case'-position in the broader debate on whether and how a multi-dimensional phenomenon, which builds on different and often incommensurable primary components, ought to be summarized in a composite indicator.

Booysen ([2], p. 131) summarizes the debate on composite indicators by noting that "not one single element of composite indexing is above criticism." And indeed, the HDI is a well-known case in point. Some authors have proposed the inclusion of other indicators in the index (e.g., Sagar and Najam [21], Dar [6]), while others have suggested indicators with a specific focus (such as poverty or gender; e.g., Klasen and Bardhan [12]). As regards the pure measurement aspects, several writers have forwarded different alternatives to the specific, 'arbitrary' normalization procedures used by the UNDP (e.g., Luchters and Menkhoff [14], Panigrahi and Sivramkrishna [20], Mazumdar [17], Chakravarty [3]), whereas others have primarily focused on the method of weighting/aggregating the different components (e.g., Noorbakhsh [19], Sagar and Najam [21], Mahlberg and Obersteiner [16], Dowrick et al. [8], Lind [13], Despotis [7], Chatterjee [4]). Again, many of the aforementioned authors particularly emphasize the effects of changes in this procedure on the resulting country ranking.

In this paper, we will also be concerned with the pure weighting/aggregation aspects and their effects on eventual country rankings. We will hence take the original quantitative indicators as given, and will sidestep the controversy over whether these are effectively suited to capture all fundamental, universally shared and measurable dimensions of human development. Although we will propose a different normalization procedure than the one that is actually used, our primary purpose is not to add yet another re-measured HDI to an already impressive list of variants. Instead, we present a methodology that precisely intends to capture the fact that there is wide disagreement about the weighting and aggregation of the HDI's components. In a specific sense, such disagreement can even be taken as a defining

\footnotetext{
${ }^{2}$ Evidently, we fully agree with the view that full accessibility to both the basic data and the specific construction methodology are good qualities: they can only enhance the credibility of a composite indicator. For similar remarks, see the OECD-European Commission's Handbook on Constructing Composite Indicators (Nardo et al. [18]).
} 
characteristic of this general type of composite indicator: one does agree that there is a complex multi-faceted issue such as, in this case, human development, and one does acknowledge that many sub-indicators, related to this overarching concept, can be discerned. But the exact (inter)relationship between these sub-indicators and that 'vague' global phenomenon is too difficult to grasp exactly; hence the real possibility of dispute, even among experts. The central contribution of this paper is exactly to present a ranking methodology that can explicitly incorporate this type of dispute by producing rankings that are robust for a wide range of opinions regarding the 'most appropriate' weighting and aggregation scheme.

We will start in Section 2 by taking each of the two well-known origins of dispute in turn. We start with the aggregation issue. In Section 2.1, we propose the aggregation of (weighted) scores using the class of increasing and S-concave indices. Thus, our multi-dimensional ranking criterion is equivalent to generalized Lorenz dominance. Proceeding as such, we seek to give foundation to the concern that it may not solely be the average, but also the distribution of the (weighted) scores in the different dimensions that must be taken into account when comparing countries. ${ }^{3}$ In Section 2.2, we address the weighting issue. Specifically, we propose a way to summarize conflicts of opinion that pertain to the question whether and how, e.g., a relatively high level of life expectancy outweighs a comparatively low literacy rate. Essentially, we allow for 'zones of agreement' (resp. 'zones of disagreement') in which there is consensus (resp. no consensus) among experts that a score in one dimension outweighs a score in another dimension. Next, in Section 3, we look at alternative methods of progressing from individual opinions to an aggregate decision rule. In particular, we suggest (1) a strong dominance criterion: country $x$ is at least as good as $y$ according to all (mutually agreed) weighting schemes and all increasing Sconcave indices, and (2) a weak dominance criterion: country $x$ is at least as good as $y$ if there exists at least one weighting scheme within the mutually agreed set of possible schemes that results in $x$ outperforming $y$ on the basis of all increasing S-concave indices. In particular, the core of our paper is concerned with identifying workable rules for the implementation of both decision criteria. Specifically, we demonstrate how these criteria translate into linear programming problems.

By the very nature of these two criteria, it is evident that in several cases one may end up with incomplete rankings. But what is gained is precisely the increased robustness of the comparisons that still can be made. Put differently, it is notably because we observe that the scientific community establishes only a limited consensus on how to gauge human development, that the tools to be presented are useful to answer the question whether one country indeed 'outperforms' another one (or itself, if one uses time series data). In Section 4 we look at the results of such exercises, using the 2002 UN data set, and illustrate the usefulness of our methodology for investigating (statistically as well as descriptively) the robustness of the United Nations' human development ranking and classification. A final Section 5 concludes.

\footnotetext{
${ }^{3}$ Maassoumi and Nickelsburg ([15], p. 328) were among the first to point out that "without this diversity in distributions there would be no need for a multi-dimensional measure." We stress that the diversity pertains to the 'inequality' among indicators and not to inter-individual inequality, e.g., of income. The same issue has been taken up recently by Chatterjee [4]. 


\section{Weights and measures}

We start with a brief sketch of the different steps to proceed from rough data to a robust ranking over countries, to wit, normalization, weighting and aggregation. Each of these steps will be discussed in the next subsections.

A country is characterized by raw data figures in each of the $n$ 'human development'-enhancing dimensions $j \in J=\{1, \ldots, n\}$. Each of these data figures is first normalized into a score vector $\mathbf{x}=\left(x_{1}, \ldots, x_{n}\right) \in \mathbb{R}_{++}^{n}$ by dividing the figure in each dimension by the median figure (over all countries) of that dimension. ${ }^{4}$ Afterwards, score vectors $\mathbf{x}$ are weighted by a weight vector $\mathbf{w}=\left(w_{1}, \ldots, w_{n}\right) \in \mathbb{R}_{++}^{n}$ to obtain weighted score vectors $\mathbf{s} \equiv\left(w_{1} x_{1}, \ldots, w_{n} x_{n}\right)$. These weights provide an indication of the (relative) importance of the $n$ dimensions when assessing the overall concept of human development. These weighted score vectors $\mathbf{s}$ are then mapped into a comparable 'human development' level via an index $I: \mathbf{s} \mapsto I$ (s). Our point of departure is the (real) fact that there is disagreement among various stakeholders about the choice of the weighting vector $\mathbf{w}$ and the aggregation index $I$. Importantly, since the scores in $\mathbf{x}$ are normalized, there could also be disagreement about this normalization. In our set-up, however, normalizing and weighting are formally equivalent procedures, so, disagreement about weighting can be equivalently set as disagreement about normalization.

\subsection{Aggregation}

Because it is necessary to understand the aggregation procedure in order to understand the implications of the weighting procedure, we start with the former issue. The issue of disagreement essentially pertains to the question as to what extent the index should be responsive to inequality among the (weighted) components. To obtain a robust criterion, we will focus on all indices $I$ which are (1) increasing and (2) $S$ concave; we collect these indicators in a set $\mathbb{I}=\{I \mid I$ is increasing and $S$-concave $\} .^{5}$ This family of indices is the basis for generalized Lorenz dominance (also called second-order stochastic dominance), which we define next for some arbitrary vectors $\mathbf{a}, \mathbf{b} \in \mathbb{R}^{n}$.

Definition 1 a generalized Lorenz dominates $\mathbf{b}$ if and only if

$$
\text { (1) } \forall I \in \mathbb{I}: I \text { (a) } \geq I \text { (b) and (2) } \exists I \in \mathbb{I}: I \text { (a) }>I \text { (b) . }
$$

This dominance criterion can be easily implemented. To see this, use $\left(a_{\langle 1\rangle}, a_{\langle 2\rangle}\right.$, $\left.\ldots, a_{\langle n\rangle}\right)$ to denote a permutation of a such that $a_{\langle 1\rangle} \leq a_{\langle 2\rangle} \leq \cdots \leq a_{\langle n\rangle}$. We have:

\footnotetext{
${ }^{4}$ Our methodology can be extended to cope with (1) 'human development'-decreasing dimensions, e.g., the number of suicides in a country, and (2) negative scores in some dimensions. In particular, such instances can be accommodated through straightforward modifications of the normalization procedure.

${ }^{5}$ An index $I$ is $S$-concave if and only if $I(B \mathbf{s}) \geq I(\mathbf{s})$, with $B$ a bistochastic matrix, i.e., rows and columns of $B$ sum up to 1 and all entries are positive.
} 
Proposition 1 a generalized Lorenz dominates $\mathbf{b}$ if and only if

(1) $\forall j \in J: \sum_{k=1}^{j} a_{\langle k\rangle} \geq \sum_{k=1}^{j} b_{\langle k\rangle}$ and (2) $\exists j \in J: \sum_{k=1}^{j} a_{\langle k\rangle}>\sum_{k=1}^{j} b_{\langle k\rangle}$.

At this point, it should be emphasized that the final outcome of our robustness tests will build on pairwise dominance comparisons rather than on checking the robustness of a country's 'index number.' As is evident from the foregoing, this is precisely because we want to check a necessary and sufficient dominance condition for a complete family of (increasing and S-concave) indices. ${ }^{6}$

We finally mention some properties of the generalized Lorenz dominance criterion. These properties are important in the sense that they already impose some structure on the weighting issue that will be considered shortly. The criterion satisfies increasingness (a higher (weighted) score in each dimension improves human development), anonymity (the names of the dimensions do not matter, or, permuting the (weighted) scores over dimensions does not alter the level of human development) and ratio-scale invariance (dividing the (weighted) scores in all dimensions by the same strictly positive scalar leaves the ranking of two countries unchanged). Note that the resulting procedure will not satisfy anonymity for the unweighted scores, but it is appropriate here because all dimensions are weighted before aggregation. Ratioscale invariance implies that we can normalize all weights to obtain, e.g., $\sum_{j \in J} w_{j}=1$.

\subsection{Weighting}

We choose to weight the score vector $\mathbf{x}$ by a weight vector $\mathbf{w}$ to obtain the weighted score vector $\mathbf{s}$ in the following specific way. Since weighting is exactly one of the modelling options surrounded by a lot of controversy in the actual debate, we will allow for a set of possible weights for each possible dimension. We will start from the thought experiment in which a set of possible weights is considered for each dimension. Specifically, consider a 'percentile' $p$, with $0 \leq p \leq 1 / 2$ and define, for each dimension $j \in J$, the set $W_{j}^{p}=\left[q_{j}^{1 / 2} / q_{j}^{1-p}, q_{j}^{1 / 2} / q_{j}^{p}\right]$ with $q_{j}^{p}$ the $p$ th quantile of the raw data figures in dimension $j$; thus $q_{j}^{1 / 2}$ is the median figure in dimension $j$. The interpretation is as follows. First, $p=1 / 2$ implies that everybody agrees to weight each dimension equally. Decreasing $p$ leads to wider weight intervals. In the end $(p=0)$ we look at weight intervals defined by dividing the median $q_{j}^{1 / 2}$ by the maximal and minimal scores $q_{j}^{0}$ and $q_{j}^{1}$, respectively, in each dimension. The set of weight vectors $\mathbf{w}=\left(w_{1}, \ldots, w_{n}\right)$ for some percentile $p$ is denoted as $W^{p}=\left\{\mathbf{w} \mid \mathbf{w} \in \times_{j \in J} W_{j}^{p}\right\}$. Two points are worth stressing regarding this set-up. First, while we model consensus by choosing $p=1 / 2$, i.e., all dimensions are equally weighted, our methodology can also handle other choices of the commonly agreed

\footnotetext{
${ }^{6}$ Our approach thus differs from the robustness tests for composite indicators as discussed by Saisana et al. [22]. Essentially, these authors consider combinations of different normalization and aggregation scenarios, and use Monte Carlo techniques to check how a country's index number changes conditional upon a change in the scenario. The end-product of such an approach is that the original index number is complemented by a confidence interval.
} 
benchmark. Second, we choose $p$ to be the same in each dimension mainly to facilitate the exposition, but one could also use $p$-values that are specific for each dimension. In general, a larger $p$-value for one dimension (compared to another dimension) suggests 'less agreement' regarding the appropriate weight for the former dimension as compared to the latter, which would thus be accounted for in the dominance evaluation.

Let us now turn to the implicit trade-offs when using this specific set-up. The case of $p=1 / 2$ is clear: all dimensions are equally weighted. In the case of the sample of our own empirical application (see Section 4), a country with a life expectancy equal to 35 years, which is $50 \%$ of the sample's median life expectancy, obtains a score of 0.5 in this dimension, while a country with a GDP per capita equal to 10,600 PPP US\$, twice the median value in our sample, obtains a score of 2 . Consider then the generalized Lorenz criterion we discussed in Section 2.1. In view of its ratio-scale invariance property, the foregoing also implies agreement about the latter (GDP) achievement being four times higher than the former (life expectancy) performance. Next, consider what happens if both scores are obtained by the same country and if we proceed to the aggregation stage. As all composite indices in the set $\mathbb{I}$ are increasing and anonymous, everyone would in that case agree that the achievement in GDP per capita must outweigh the achievement in life expectancy.

Finally, and importantly, the same reasoning carries over to compare different countries. That is, given a specific weight vector $\mathbf{w}$ and applying this to two countries with respective score vectors $\mathbf{x}$ and $\mathbf{y}$, the proposed framework entails that the former score vector weakly dominates the latter in the generalized Lorenz sense (and conditional on the choice of weights) if and only if

$$
\sum_{k=1}^{j}\left(w_{k} x_{k}\right)_{\langle k\rangle} \geq \sum_{k=1}^{j}\left(w_{k} y_{k}\right)_{\langle k\rangle} \text { for all } j \in J
$$

So far, we have focused on the 'full agreement' scenario. Yet, this defies a lot of the actual debates, so that other scenarios must be allowed for. Our set-up easily embeds some of the real-life controversies by decreasing $p$. More specifically, we select lower values for $p$ to introduce doubt about the exact implicit price of the different dimensions. For example, choosing $p=1 / 4$ (the interquartile range), leads to a situation where the weights in dimension $j$ lie in $\left[q_{j}^{1 / 2} / q_{j}^{3 / 4}, q_{j}^{1 / 2} / q_{j}^{1 / 4}\right]$. As a consequence, there is no longer full agreement regarding the exact trade-off between, e.g., life expectancy achievement and GDP performance.

\section{Robust outranking criteria}

The dominance criterion of Section 2.1. is based on pairwise country comparisons of (sums of) ordered weighted scores. The approach in Section 2.2. essentially boils down to the statement that we allow for several possible scenarios regarding the weighting of these scores. We can now put the different pieces of the puzzle together. At this final stage, we need to define an explicit decision rule that takes the diversity of opinions into account. We will here define two dominance criteria, a strong one and a weak one, and will subsequently indicate how these can be implemented. 
The strong criterion is inspired by Fleurbaey et al.'s [9] generalized Lorenz dominance criterion with bounded equivalence scales to compare income distributions over households that differ in needs. We here adapt it to multi-dimensional comparisons of human development performances. In words, we say that a country (generalized Lorenz) dominates another country in a strongly robust sense if it does so for every possible weighting vector, while the former country does not dominate the latter country for some weighting vector. By a 'possible weighting vector' we mean a weighting vector that belongs to the set $W^{p}$. Intuitively, this means that it will be harder for a country to outperform another one as the disagreement about 'possible weighting schemes' increases. Indeed, as we have already stated in the introduction, one is likely to end up with an incomplete ordering of countries. The same idea can be stated alternatively as follows: as zones of disagreement get wider, a country's raw data rather than the analyst's normative modelling options become increasingly important in assessing that country's relative position in the sample. This is indeed a plausible way to think about the robustness problem.

We also consider a different approach. The robustness issue is ultimately rooted in the uncertainty surrounding the construction of the index, as reflected by allowing for a set of different weighting schemes. It is therefore arguable whether the strong criterion itself is convincing in all cases. For instance, while one country might not dominate another one for every possible weighting vector, it might do so for a subset of those weighting vectors, without a similar but reverse relationship holding. Carrying this reasoning to its extreme, we will thus also present a weak variant, which states that a country dominates another in a weakly robust sense if it does so for at least one possible weighting vector, while the opposite dominance relationship does not occur. In contrast with the strong dominance criterion, the weak version looks for support rather than unanimity in terms of the possible weighting schemes. We may regard this weak criterion as conservative, in that it maintains dominance of the former country over the latter as long as there exists at least one possible weighting scheme that supports this conclusion. In a sense, it allows countries with a different policy mix, and thus an outstanding performance in one of the dimensions, to put more weight on its best dimension in order to outperform other countries. Note that one can also refer to the robustness concern here: if a country is judged to have been outperformed on the basis of this weak criterion, it is far more due to its (feeble) raw data rather than to the composite index's artificiality. ${ }^{7}$

We first define the strong criterion. As introduced informally above, it states that a country with a weighted score vector $\mathbf{x}$ strongly dominates another country with a weighted score vector $\mathbf{y}$ if and only if (1) $\mathbf{x}$ is at least as good as $\mathbf{y}$ according to all mutually agreed weighting vectors (in $W^{p}$, with $0 \leq p \leq \frac{1}{2}$ ) and all indices (in II) and (2) not the other way around, or, there exists at least one weighting vector and one index such that $\mathbf{x}$ is strictly better than $\mathbf{y}$. We get:

Definition $2 \mathbf{x}$ strongly dominates $\mathbf{y}$ for some $p, 0 \leq p \leq \frac{1}{2}$, denoted $\mathbf{x} \succ_{*}^{p} \mathbf{y}$, if and only if

\footnotetext{
${ }^{7}$ This weak version is inspired by Cherchye et al. [5]. Specifically, focussing on a linear aggregation index, these authors suggest the endogenous selection of the most favorable linear aggregation weights. Here, we generalize this idea towards S-concave aggregation indices.
} 
(1) ${ }_{*}^{p} \quad \forall \mathbf{w} \in W^{p}$ and $\forall I \in \mathbb{I}: I\left(w_{1} x_{1}, \ldots, w_{n} x_{n}\right) \geq I\left(w_{1} y_{1}, \ldots, w_{n} y_{n}\right)$,

$(2)_{*}^{p} \quad \exists \mathbf{w} \in W^{p}$ and $\exists I \in \mathbb{I}: I\left(w_{1} x_{1}, \ldots, w_{n} x_{n}\right)>I\left(w_{1} y_{1}, \ldots, w_{n} y_{n}\right)$.

Notice again that decreasing $p$ increases the weighting vector set and makes the criterion more robust, but at the cost of completeness. More precisely, for all $p, q$ with $0 \leq p \leq q \leq \frac{1}{2}$, and for all $\mathbf{x}, \mathbf{y} \in \mathbb{R}_{++}^{n}$ we have $\mathbf{x} \succ_{*}^{p} \mathbf{y} \Rightarrow \mathbf{x} \succ_{*}^{q} \mathbf{y}^{8}$ In the end, $\succ_{*}^{0}$ is equal to the unanimity criterion: a country dominates another country if and only if the former dominates the latter in each dimension separately.

The strong dominance criterion $\succ_{*}^{p}$ corresponds with verifying generalized Lorenz dominance (see Proposition 1) for the 'least favorable' weighting vector. We provide the basic intuition. For example, in order for $(1)_{*}^{p}$ to be true, weak generalized Lorenz dominance must hold for any of the mutually agreed weighting vectors, i.e.:

$$
\sum_{k=1}^{j}\left(w_{k} x_{k}\right)_{\langle k\rangle}-\sum_{k=1}^{j}\left(w_{k} y_{k}\right)_{\langle k\rangle} \geq 0 \text { for all } \mathbf{w} \in W^{p} \text { and for all } j \in J .
$$

It is fairly intuitive that it suffices, for each $j$, to check this inequality for the specific weighting vector that minimizes the left hand term (rather than to consider all $w \in W^{p}$ ). Elaborating on this intuition, we obtain the next proposition, which essentially combines Definitions 1 and 2 into an equivalent condition based on min and max operators. The notation $S_{j}(J)$ stands for the set containing all subsets $K \subseteq J$ with cardinality $j$. (Complete proofs of all the following propositions can be found in Appendix A)

Proposition 2A (1) ${ }_{*}^{p}$ holds if and only if

$$
\max _{j \in J} \max _{K \in S_{j}(J)} \max _{\mathbf{w} \in W^{p}}\left[\min _{L \in S_{j}(J)}\left(\sum_{\ell \in L} w_{\ell} y_{\ell}\right)-\sum_{k \in K} w_{k} x_{k}\right] \leq 0,
$$

while $(2)_{*}^{p}$ holds if and only if

$$
\max _{j \in J} \max _{L \in S_{j}(J)} \max _{\mathbf{w} \in W^{p}}\left[\min _{K \in S_{j}(J)}\left(\sum_{k \in K} w_{k} x_{k}\right)-\sum_{\ell \in L} w_{\ell} y_{\ell}\right]>0 .
$$

The next result states that, starting from the specific structure of the conditions in Proposition 2A, the strong dominance criterion $\succ_{*}^{p}$ can be implemented via linear programming techniques.

Proposition 2B $\mathbf{x}$ strongly dominates $\mathbf{y}$ for some $p, 0 \leq p \leq \frac{1}{2}$, denoted $\mathbf{x} \succ_{*}^{p} \mathbf{y}$, if and only if

$(1)_{*}^{p} \quad \varepsilon_{*}^{p}(\mathbf{x}, \mathbf{y}) \leq 0$ and $(2)_{*}^{p} \varepsilon_{*}^{p}(\mathbf{y}, \mathbf{x})>0$, with (for arbitrary $\left.\mathbf{a}, \mathbf{b} \in \mathbb{R}^{n}\right)$

\footnotetext{
${ }^{8}$ While our main discussion focuses on the same $p$ in all dimensions for ease of exposition, it is worth noting that a similar mechanism applies when using dimension-specific $p$-values. More specifically, increasing the $p$-value of some dimension then ceteris paribus reflects 'more disagreement' regarding the appropriate weight for that dimension (relative to the other dimensions) and, hence, will result in a less complete (strong dominance) ordering.
} 


$$
\begin{aligned}
\varepsilon_{*}^{p}(\mathbf{a}, \mathbf{b})= & \max _{j \in J} \max _{K \in S_{j}(J)} \max _{\mathbf{w} \in W^{p}} \alpha \quad \text { subject to } \\
& \beta \leq \sum_{\ell \in L} w_{\ell} b_{\ell}, \forall L \in S_{j}(J) \quad \text { and } \quad \alpha \leq \beta-\sum_{k \in K} w_{k} a_{k} .
\end{aligned}
$$

Formally, the weak 'conservative' dominance criterion states that a country with score vector $\mathbf{x}$ weakly dominates another country with vector $\mathbf{y}$ if and only if there exists a weighting vector (in $W^{p}$, with $0 \leq p \leq \frac{1}{2}$ ) such that $\mathbf{x}$ is at least as good as $\mathbf{y}$ for all indices (in $\mathbb{I}$ ) and (2) not the other way around, or, for each weighting vector there exists vector at least one index such that $\mathbf{x}$ is strictly better than $\mathbf{y}$. We get:

Definition $3 \mathbf{x}$ weakly dominates $\mathbf{y}$ for some $p, 0 \leq p \leq \frac{1}{2}$, denoted $\mathbf{x} \succ^{p} \mathbf{y}$, if and only if

(1) $)^{p} \exists \mathbf{w} \in W^{p}$ such that $\forall I \in \mathbb{I}: I\left(w_{1} x_{1}, \ldots, w_{n} x_{n}\right) \geq I\left(w_{1} y_{1}, \ldots, w_{n} y_{n}\right)$,

(2) $)^{p} \quad \forall \mathbf{w} \in W^{p}: \exists I \in \mathbb{I}$ such that $I\left(w_{1} x_{1}, \ldots, w_{n} x_{n}\right)>I\left(w_{1} y_{1}, \ldots, w_{n} y_{n}\right)$.

Notice that weak dominance extends strong dominance, i.e., for some given $p, 0 \leq$ $p \leq \frac{1}{2}$ and for all $\mathbf{x}, \mathbf{y} \in \mathbb{R}_{++}^{n}$ we have $\mathbf{x} \succ_{*}^{p} \mathbf{y} \Rightarrow \mathbf{x} \succ^{p} \mathbf{y}$. But weak dominance might also introduce cycles, i.e., a sequence of countries $\mathbf{x}^{1}, \mathbf{x}^{2}, \ldots, \mathbf{x}^{k}$ such that $\mathbf{x}^{1} \succ^{p} \mathbf{x}^{2} \succ^{p}$ $\cdots \succ^{p} \mathbf{x}^{k} \succ^{p} \mathbf{x}^{1}$. Finally given $p, q$ with $0 \leq p \leq q \leq \frac{1}{2}$, there is no relation between $\succ^{p}$ and $\succ^{q}$ anymore.

Attractively, the weak dominance criterion $\succ^{p}$ can also be implemented via linear programming techniques, but here verifying generalized Lorenz dominance for the 'most favorable' weighting vector. Define $\Pi(J)$, the set containing all permutations $\pi: J \rightarrow J: k \mapsto \pi(k)$.

Proposition 3A (1) ${ }^{p}$ holds if and only if

$$
\max _{j \in J} \min _{\pi \in \Pi(J)} \min _{\mathbf{w} \in W^{p}}\left[\sum_{\ell=1}^{j} w_{\pi(\ell)} y_{\pi(\ell)}-\min _{K \in S_{j}(J)}\left(\sum_{k \in K} w_{k} x_{k}\right)\right] \leq 0,
$$

while $(2)^{p}$ holds if and only if

$$
\max _{j \in J} \min _{\pi \in \Pi(J)} \min _{\mathbf{w} \in W^{p}}\left[\sum_{\ell=1}^{j} w_{\pi(\ell)} x_{\pi(\ell)}-\min _{K \in S_{j}(J)}\left(\sum_{k \in K} w_{k} y_{k}\right)\right]>0 .
$$

This can be implemented as follows:

Proposition 3B $\mathbf{x}$ weakly dominates $\mathbf{y}$ for some $p, 0 \leq p \leq \frac{1}{2}$, denoted $\mathbf{x} \succ^{p} \mathbf{y}$, iff $(1)^{p} \quad \varepsilon^{p}(\mathbf{x}, \mathbf{y}) \geq 0$ and $(2)^{p} \varepsilon^{p}(\mathbf{y}, \mathbf{x})<0$, with (for arbitrary vectors $\mathbf{a}, \mathbf{b} \in \mathbb{R}_{++}^{n}$ )

$$
\begin{aligned}
\varepsilon^{p}(\mathbf{a}, \mathbf{b}) & =\max _{j \in J} \min _{\pi \in \Pi(J)} \min _{\mathbf{w} \in W^{p}} \alpha \quad \text { subject to } \\
\beta & \leq \sum_{k \in K} w_{k} a_{k}, \forall K \in S_{j}(J) \quad \text { and } \quad \alpha \geq \sum_{\ell=1}^{j} w_{\pi(\ell)} b_{\pi(\ell)}-\beta .
\end{aligned}
$$


We conclude with an illustrative example. Specifically, we compare South Africa and Kuwait, two countries taken from our data set discussed in Section 4. For each of these two countries, Table 1 presents the non-normalized values for the three variables captured by the HDI, which are also used in our following application. In addition, it gives summary information on the distributions of the three variables as defined over the full sample of 177 countries. This is the information that we use for illustrating the robust outranking criteria.

As a first step, we construct the normalized scores for each country, which are obtained by dividing the country-specific figures in each dimension by the respective median figures (over all countries). The resulting scores can be found in Table 2 .

Let us then regard the strongly robust dominance criterion of Definition 2. We first consider $\succ_{*}^{0}(p=0)$; as discussed above, this corresponds to full disagreement regarding the appropriate weighting scheme, and boils down to checking the unanimity criterion. As for this specific example, we find that no country dominates the other country in all dimensions simultaneously, i.e., the two countries are noncomparable in terms of $\succ_{*}^{0}$. We next consider the other extreme scenario with $p=1 / 2$, which we have indicated as the full agreement (or 'consensus') scenario. Checking dominance in terms of $\succ_{*}^{1 / 2}$ boils down to verifying the inequalities in Proposition 1 for the (permuted) normalized scores tabulated above. Setting $p=1 / 2$ in our set-up captures the fact that all normalized dimensions are equally weighted, as, to recall, is the specific position taken in the construction of the actual HDI. The latter would then proceed by summing these equally weighted scores. In our set-up, this is but one of the relevant summations (recall Eq. 1). Applying our approach yields that Kuwait robustly dominates South Africa (because $0.95>0.70$, $0.95+1.09>0.70+0.98$ and $0.95+1.09+3.06>0.70+0.98+1.90)$. Thus, in the unlikely case of complete consensus regarding the weighting scheme $(p=1 / 2)$, this dominance conclusion is 'robust' in that it holds for any increasing and $S$-concave aggregation index.

However, as argued before, full agreement and full disagreement are unlikely to occur in practice. The core contribution of our approach is precisely that it allows for robust dominance evaluation when there is some (but not full) disagreement regarding the appropriate weighting scheme (i.e. $0<p<1 / 2$ ). To illustrate this case, we consider the intermediate criterion $\succ_{*}^{1 / 4}$. Given Proposition 2 , this requires solving a series of linear programming problems. We illustrate the computation of $\varepsilon_{*}^{1 / 4}(\mathbf{x}, \mathbf{y})$ in Proposition 2 for $\mathbf{x}$ the normalized score vector of Kuwait and $\mathbf{y}$ the

Table 1 An illustrative example: South Africa and Kuwait

\begin{tabular}{lllr}
\hline & $\begin{array}{l}\text { Life expectancy } \\
\text { (years) }\end{array}$ & $\begin{array}{l}\text { Educational achievement } \\
(\%)\end{array}$ & $\begin{array}{l}\text { GDP per capita } \\
\text { (PPP US\$) }\end{array}$ \\
\hline South Africa & 48.80 & 83.00 & 10.07 \\
Kuwait & 76.50 & 80.60 & 16.24 \\
Minimum & 32.70 & 15.87 & 0.48 \\
1st quartile & 57.40 & 65.93 & 1.99 \\
Median & 70.00 & 84.40 & 5.30 \\
3rd quartile & 74.00 & 91.00 & 12.26 \\
Maximum & 81.50 & 99.33 & 40.00 \\
\hline
\end{tabular}


Table 2 Normalized figures as derived from the data in Table 1

\begin{tabular}{llll}
\hline & Life expectancy & Educational achievement & GDP per capita \\
\hline South Africa & 0.70 & 0.98 & 1.90 \\
Kuwait & 1.09 & 0.95 & 3.06 \\
\hline
\end{tabular}

normalized score vector of South Africa; in casu $n=3$ and thus $J=\{1,2,3\}$. Let $j=3$ for the first max operator, so that for the second max operator $S_{3}(J)=\{J\}$. The third max operator then complies with the linear programming problem

$$
\begin{aligned}
\theta & =\max _{w_{1}, w_{2}, w_{3}} \alpha \\
\text { s.t. } \beta & \leq 0.70 w_{1}+0.98 w_{2}+1.90 w_{3} \\
\alpha & \leq \beta-\left(1.09 w_{1}+0.95 w_{2}+3.06 w_{3}\right) \\
0.95 & \leq w_{1} \leq 1.22,0.93 \leq w_{2} \leq 1.28,0.43 \leq w_{3} \leq 2.66
\end{aligned}
$$

The outcome of this problem is $\theta=-0.83$ (for $\beta=2.74, w_{1}=0.95, w_{2}=1.28$ and $\left.w_{3}=0.43\right)$. According to Proposition $2, \theta \leq 0$ is a necessary condition for $\varepsilon_{*}^{1 / 4}(\mathbf{x}, \mathbf{y}) \leq$ 0 , and so for obtaining that $\mathbf{x}$ strongly robustly dominates $\mathbf{y}$ (for $p=1 / 4$ ). A necessary and sufficient condition for $\varepsilon_{*}^{1 / 4}(\mathbf{x}, \mathbf{y}) \leq 0$ involves analogously constructed linear programming problems for $j=1$ and $j=2$ for the first max operator (and correspondingly defined $S_{1}(J)$ and $S_{2}(J)$ for the second max operator). It can be verified that this procedure effectively yields $\varepsilon_{*}^{1 / 4}(\mathbf{x}, \mathbf{y}) \leq 0$. Similarly, we can find that $\varepsilon_{*}^{1 / 4}(\mathbf{y}, \mathbf{x})>0$. Hence, we conclude that Kuwait strongly dominates South Africa for $p=1 / 4$. Thus even if there is disagreement on the exact relative importance of the different human development dimensions, Kuwait's scores are such that it outperforms South Africa, for any weight vector taken from the (agreed) set $W^{1 / 4}$ and for any increasing and $S$-concave index.

We next turn to the weakly robust dominance criterion in Definition 3. Using Proposition 3, for a given specification of $p$ this again requires solving a series of linear programming problems, one problem per permutation $\pi \in \Pi(J)$; the construction of each (in casu minimization) problem is directly analogous as before. Computing $\varepsilon^{p}(\mathbf{x}, \mathbf{y})$ and $\varepsilon^{p}(\mathbf{y}, \mathbf{x})$ for our two-country example, we obtain that Kuwait weakly dominates South Africa for $p=0, p=1 / 2$ as well as $p=1 / 4$. Put otherwise, the message here is that, even with extremely large disagreement about weighting, there exists a weight vector for which Kuwait outperforms South Africa for all increasing and $S$-concave indices, while the opposite is not true.

\section{An illustrative application to UN 2002 data}

As stated in the introduction, the media are eager to focus on the HDI-country rankings each time a new HDR is released. Media headlines (and official press releases as well) often have a clear hit-parade flavor ("For the fifth year in a row, Norway leads," "Niger displaced Sierra Leone at the bottom," "the Netherlands: down seven places!,"...). But to what extent do such hit-parades hinge on the specific modelling options? Are some countries mistreated, in the sense that their relative 
ranking would change conditional upon a change in such modelling options? As stated above, these kinds of questions have been the subject of considerable research. In this section, we will use the tools developed above to investigate the extent to which country comparisons can still be made if one embeds modelling uncertainty from the very beginning. Our application uses the $2002 \mathrm{UN}$-dataset, which contains the life expectancy at birth (in years), the educational achievement (in \%) - a weighted average of the adult literacy rate (\% with weight $2 / 3$ ) and the gross school enrolment rate (\% with weight $1 / 3$ ) - and the adjusted gross domestic product per capita (in PPP US\$) for 177 countries. ${ }^{9}$

Recall that our check for consistency with generalized Lorenz dominance (i.e., with a class of indices) implies that we will not produce an index number as such. What we can produce, using this general test, are pairwise dominance results: a country may outperform another one, or the reverse, or there is no robust dominance relation between the two countries considered. Rather than overwhelming the reader with huge dominance tables, in the next subsection we will explore the robustness of the HDI ranking for two specific groups of countries, namely 24 OECD and 45 sub-Saharan African countries. ${ }^{10}$ A descriptive analysis of the pairwise dominance relationships within these two country groups, which for the most part are situated at the two extremes of the UN HDI rankings, should provide some first insight into the robustness of the HDI. The second subsection looks at the full sample of 177 countries. There we complement the former descriptive analysis by statistical tests of the HDI's robustness. We will be concerned with two types of robustness assessment. First, we will address robustness of the HDI country ranking itself. Second, we will take a broader view and ask whether the HDI's classification of countries (into low, middle and high human development classes) is robust. In both subsections we use the strong and weak dominance criteria, and we capture disagreement by considering $p=1 / 4$ (which corresponds to the interquartile range for defining the set of possible weight vectors). ${ }^{11}$

\subsection{Weakly and strongly robust dominance: OECD and sub-Saharan Africa}

We start with the OECD countries. Table 3 shows the strong pairwise dominance relationships and Table 4 the weak relationships (according to $\succ_{*}^{1 / 4}$ and $\succ^{1 / 4}$ ) for 24 OECD countries. A ' 1 ' means that the corresponding row country dominates the column country, while a ' 0 ' means that the corresponding row and column countries cannot be compared.

\footnotetext{
${ }^{9}$ These data are downloadable at http://hdr.undp.org/statistics/data/.

${ }^{10}$ Some summary information about dominance for the complete sample is provided in Appendix B. Specifically, for the (extreme) criteria $\succ_{*}^{0}$ and $\succ^{0}$ we there tabulate for each country the number of observations that are (robustly) dominated by that country and the number of observations that are dominating the country. In addition, we rank the countries for each criterion on the basis of a net dominance metric, i.e., the number of dominated observations minus the number of dominating observations.

${ }^{11}$ Recall from our discussion in Section 2.2 that $p=1 / 2$ and $p=0$ correspond to the extreme scenarios of, respectively, full agreement and full disagreement regarding the appropriate weighting scheme. We choose to focus on the intermediate scenario $p=1 / 4$ given the mainly illustrative purpose of this application.
} 
Table 3 Strong dominance relation $\succ_{*}^{1 / 4}$ for OECD subsample $(0=$ row element does not dominate column element; 1 = row element dominates column element)

\begin{tabular}{|c|c|c|c|c|c|c|c|c|c|c|c|c|c|c|c|c|c|c|c|c|c|c|c|}
\hline 1 & Norway & & 0 & & & 0 & & 0 & 1 & 0 & 0 & 0 & 1 & 0 & 1 & 1 & 0 & 1 & 0 & 1 & 1 & 1 & 1 \\
\hline 2 & Sweden & 0 & & 0 & 0 & 0 & $\begin{array}{lll}0 & 0\end{array}$ & 0 & 0 & 0 & 0 & 0 & 0 & 0 & 0 & 0 & 1 & 0 & 1 & 0 & 1 & 1 & 1 \\
\hline 3 & Australia & 0 & 0 & ( & 0 & 1 & & 0 & 0 & 0 & 1 & 1 & 0 & 0 & 1 & 0 & 1 & 1 & 0 & 1 & 1 & 1 & 1 \\
\hline 4 & Canada & 0 & 0 & 0 & 0 & 0 & 00 & 0 & 0 & 0 & 0 & 0 & 1 & 0 & 1 & 0 & 0 & 1 & 1 & 1 & 1 & 1 & 1 \\
\hline 5 & Netherlands & 0 & 0 & 0 & 0 & 0 & $\begin{array}{lll}0 & 0\end{array}$ & 0 & 0 & 0 & 0 & 0 & 0 & 0 & 0 & 0 & 0 & 1 & 0 & 0 & 1 & 1 & 1 \\
\hline 6 & Belgium & 0 & 0 & 0 & $\begin{array}{ll}0 & 0\end{array}$ & & $\begin{array}{lll}0 & 0\end{array}$ & 0 & 0 & 0 & 1 & 1 & 0 & 0 & 0 & 0 & 1 & 1 & 0 & 1 & 1 & 1 & 1 \\
\hline 7 & Iceland & 0 & 0 & & $\begin{array}{ll}0 & 0\end{array}$ & & & 0 & 0 & 0 & 0 & 0 & 0 & 0 & 0 & 0 & 0 & 1 & 0 & 1 & 1 & 0 & 0 \\
\hline 8 & United States & 0 & 0 & 0 & $\begin{array}{ll}0 & 0\end{array}$ & 0 & & 0 & 0 & 0 & 0 & 0 & 0 & 0 & 0 & 0 & 0 & 0 & 0 & 0 & 0 & 0 & 1 \\
\hline 9 & Japan & 0 & 0 & 0 & $\begin{array}{lll}0 & 0\end{array}$ & 0 & $\begin{array}{lll}0 & 0\end{array}$ & & 0 & 0 & 0 & 0 & 0 & 0 & 0 & 0 & 0 & 0 & 0 & 1 & 0 & 0 & 0 \\
\hline 10 & Ireland & 0 & 0 & 0 & $\begin{array}{ll}0 & 0\end{array}$ & 0 & $\begin{array}{lll}0 & 0\end{array}$ & 0 & & 0 & 0 & 0 & 0 & 0 & 0 & 0 & 0 & 0 & 0 & 0 & 0 & 0 & 0 \\
\hline 11 & Switzerland & 0 & 0 & 0 & $\begin{array}{ll}0 & 0\end{array}$ & 0 & $\begin{array}{ll}0 & 0\end{array}$ & 0 & 0 & & 0 & 0 & 0 & 0 & 0 & 0 & 0 & 1 & 0 & 1 & 1 & 0 & 0 \\
\hline 12 & United Kingdom & 0 & 0 & 0 & $\begin{array}{ll}0 & 0\end{array}$ & 0 & $\begin{array}{lll}0 & 0\end{array}$ & 0 & 0 & 0 & & 0 & 0 & 0 & 0 & 0 & 0 & 0 & 0 & 0 & 0 & 1 & 1 \\
\hline 13 & Finland & 0 & 0 & 0 & $\begin{array}{ll}0 & 0\end{array}$ & 0 & $\begin{array}{lll}0 & 0\end{array}$ & 0 & 0 & 0 & 0 & & 0 & 0 & 0 & 0 & 0 & 0 & 0 & 0 & 0 & 1 & 1 \\
\hline 14 & Austria & 0 & 0 & 0 & $\begin{array}{ll}0 & 0\end{array}$ & 0 & $\begin{array}{lll}0 & 0\end{array}$ & 0 & 0 & 0 & 0 & 0 & & 0 & 0 & 0 & 0 & 1 & 0 & 0 & 1 & 0 & 0 \\
\hline 15 & Luxembourg & 0 & 0 & 0 & $\begin{array}{ll}0 & 0\end{array}$ & 0 & $\begin{array}{lll}0 & 0\end{array}$ & 0 & 0 & 0 & 0 & 0 & 0 & & 0 & 0 & 0 & 0 & 0 & 0 & 0 & 0 & 0 \\
\hline 16 & France & 0 & 0 & 0 & $\begin{array}{ll}0 & 0\end{array}$ & 0 & $\begin{array}{lll}0 & 0\end{array}$ & 0 & 0 & 0 & 0 & 0 & 0 & 0 & & 0 & 0 & 0 & 0 & 1 & 1 & 0 & 0 \\
\hline 17 & Denmark & 0 & 0 & 0 & $\begin{array}{ll}0 & 0\end{array}$ & 0 & $\begin{array}{lll}0 & 0\end{array}$ & 0 & 0 & 0 & 0 & 0 & 0 & 0 & 0 & & 0 & 0 & 0 & 0 & 0 & 1 & 1 \\
\hline 18 & New Zealand & 0 & 0 & 0 & $\begin{array}{lll}0 & 0\end{array}$ & 0 & 00 & 0 & 0 & 0 & 0 & 0 & 0 & 0 & 0 & 0 & & 0 & 0 & 0 & 1 & 1 & 1 \\
\hline 19 & Germany & 0 & 0 & 0 & $\begin{array}{ll}0 & 0\end{array}$ & 0 & $\begin{array}{lll}0 & 0\end{array}$ & 0 & 0 & 0 & 0 & 0 & 0 & 0 & 0 & 0 & 0 & & 0 & 0 & 1 & 0 & 0 \\
\hline 20 & Spain & 0 & 0 & 0 & $\begin{array}{ll}0 & 0\end{array}$ & 0 & $\begin{array}{lll}0 & 0\end{array}$ & 0 & 0 & 0 & 0 & 0 & 0 & 0 & 0 & 0 & 0 & 0 & & 0 & 1 & 0 & 1 \\
\hline 21 & Italy & 0 & 0 & 0 & $\begin{array}{ll}0 & 0\end{array}$ & 0 & $\begin{array}{lll}0 & 0\end{array}$ & 0 & 0 & 0 & 0 & 0 & 0 & 0 & 0 & 0 & 0 & 0 & 0 & & 0 & 0 & 0 \\
\hline 22 & Greece & 0 & 0 & 0 & $\begin{array}{ll}0 & 0\end{array}$ & 0 & $\begin{array}{lll}0 & 0\end{array}$ & 0 & 0 & 0 & 0 & 0 & 0 & 0 & 0 & 0 & 0 & 0 & 0 & 0 & & 0 & 0 \\
\hline 23 & Portugal & 0 & 0 & 0 & $\begin{array}{ll}0 & 0\end{array}$ & 0 & 00 & 0 & 0 & 0 & 0 & 0 & 0 & 0 & 0 & 0 & 0 & 0 & 0 & 0 & 0 & & 1 \\
\hline 24 & Korea, Rep. of & 0 & & 0 & $\begin{array}{ll}0 & 0\end{array}$ & 0 & $\begin{array}{lll}0 & 0\end{array}$ & & 0 & 0 & 0 & 0 & 0 & 0 & 0 & 0 & 0 & 0 & 0 & 0 & 0 & 0 & \\
\hline
\end{tabular}

Table 4 Weak dominance relation $\succ_{*}^{1 / 4}$ for OECD subsample $(0=$ row element does not dominate column element; 1 = row element dominates column element)

$\begin{array}{llllllllllllllllllllllllllll}1 & 2 & 3 & 4 & 5 & 6 & 7 & 8 & 9 & 10 & 11 & 12 & 13 & 14 & 15 & 16 & 17 & 18 & 19 & 20 & 21 & 22 & 23 & 24\end{array}$

\begin{tabular}{|c|c|c|c|c|c|c|c|c|c|c|c|c|c|c|c|c|c|c|c|c|c|c|}
\hline 1 & Norway & & 00 & & & & & 1 & 1 & 1 & 1 & 1 & 1 & 0 & 1 & 1 & 1 & 1 & 1 & 1 & 1 & 1 \\
\hline 2 & Sweden & 0 & & 00 & 0 & 0 & 00 & 0 & 0 & 0 & 1 & 1 & 0 & 0 & 0 & 0 & 1 & 1 & 1 & 1 & 1 & 1 \\
\hline 3 & Australia & 0 & 0 & 0 & 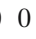 & 1 & 00 & 1 & 0 & 0 & 1 & 1 & 0 & 0 & 1 & 0 & 1 & 1 & 1 & 1 & 1 & 1 \\
\hline 4 & Canada & 0 & $\begin{array}{ll}0 & 0\end{array}$ & 0 & 0 & 0 & $\begin{array}{ll}0 & 0\end{array}$ & 1 & 0 & 0 & 0 & 1 & 1 & 0 & 1 & 0 & 0 & 1 & 1 & 1 & 1 & 1 \\
\hline 5 & Netherlands & 0 & $\begin{array}{ll}0 & 0\end{array}$ & 00 & & 0 & $\begin{array}{ll}0 & 0\end{array}$ & 1 & 0 & 0 & 0 & 1 & 1 & 0 & 1 & 0 & 0 & 1 & 1 & 1 & 1 & 1 \\
\hline 6 & Belgium & 0 & 00 & 00 & 0 & & 00 & 01 & 0 & 0 & 1 & 1 & 0 & 0 & 1 & 0 & 1 & 1 & 1 & 1 & 1 & 1 \\
\hline 7 & Iceland & 0 & & 00 & 0 & 0 & 0 & 00 & 0 & 0 & 0 & 0 & 1 & 0 & 1 & 0 & 0 & 1 & 0 & 1 & 1 & 1 \\
\hline 8 & United States & 0 & 00 & 00 & 0 & 0 & 0 & 0 & 0 & 0 & 0 & 0 & 0 & 0 & 0 & 0 & 0 & 0 & 0 & 1 & 1 & 1 \\
\hline 9 & Japan & 0 & $\begin{array}{ll}0 & 0\end{array}$ & 00 & 0 & 0 & 00 & & 0 & 0 & 0 & 0 & 0 & 0 & 1 & 0 & 0 & 1 & 1 & 1 & 1 & 1 \\
\hline 10 & Ireland & 0 & 00 & 00 & 0 & 0 & 00 & 0 & & 0 & 0 & 0 & 0 & 0 & 0 & 0 & 0 & 0 & 0 & 1 & 0 & 1 \\
\hline 11 & Switzerland & 0 & 00 & 00 & 0 & 0 & 00 & 0 & 0 & & 0 & 0 & 0 & 0 & 0 & 0 & 0 & 1 & 0 & 1 & 1 & 1 \\
\hline 12 & United Kingdom & 0 & 00 & 00 & 0 & 0 & 00 & 0 & 0 & 0 & & 1 & 0 & 0 & 0 & 0 & 0 & 0 & 1 & 1 & 1 & 1 \\
\hline 13 & Finland & 0 & 00 & 00 & 0 & 0 & 00 & 0 & 0 & 0 & 0 & & 0 & 0 & 0 & 0 & 0 & 0 & 1 & 1 & 1 & 1 \\
\hline 14 & Austria & 0 & 00 & $\begin{array}{ll}0 & 0\end{array}$ & 0 & 0 & 00 & 0 & 0 & 0 & 0 & 0 & & 0 & 0 & 0 & 0 & 1 & 0 & 1 & 1 & 1 \\
\hline 15 & Luxembourg & 0 & $\begin{array}{lll}0 & 0\end{array}$ & 00 & 0 & 0 & $\begin{array}{ll}0 & 0\end{array}$ & 0 & 0 & 0 & 0 & 0 & 0 & & 0 & 0 & 0 & 0 & 0 & 0 & 0 & 0 \\
\hline 16 & France & 0 & $\begin{array}{ll}0 & 0\end{array}$ & $\begin{array}{ll}0 & 0\end{array}$ & 0 & 0 & $\begin{array}{ll}0 & 0\end{array}$ & 0 & 0 & 0 & 0 & 0 & 0 & 0 & & 0 & 0 & 1 & 0 & 1 & 1 & 1 \\
\hline 17 & Denmark & 0 & & $\begin{array}{ll}0 & 0\end{array}$ & 0 & 0 & 00 & 0 & 0 & 0 & 0 & 0 & 0 & 0 & 0 & & 0 & 1 & 0 & 1 & 1 & 1 \\
\hline 18 & New Zealand & 0 & 00 & $\begin{array}{ll}0 & 0\end{array}$ & 0 & 0 & 00 & 0 & 0 & 0 & 0 & 0 & 0 & 0 & 0 & 0 & & 0 & 1 & 0 & 1 & 1 \\
\hline 19 & Germany & 0 & & 00 & 0 & 0 & $\begin{array}{ll}0 & 0\end{array}$ & 0 & 0 & 0 & 0 & 0 & 0 & 0 & 0 & 0 & 0 & & 0 & 1 & 1 & 1 \\
\hline 20 & Spain & 0 & & 00 & 0 & 0 & 00 & 0 & 0 & 0 & 0 & 0 & 0 & 0 & 0 & 0 & 0 & 0 & & 0 & 1 & 1 \\
\hline 21 & Italy & 0 & & 00 & 0 & 0 & 00 & 0 & 0 & 0 & 0 & 0 & 0 & 0 & 0 & 0 & 0 & 0 & 0 & & 0 & 0 \\
\hline 22 & Greece & 0 & & 00 & 0 & 0 & 00 & 0 & 0 & 0 & 0 & 0 & 0 & 0 & 0 & 0 & 0 & 0 & 0 & 0 & & 1 \\
\hline 23 & Portugal & 0 & & 00 & 0 & 0 & 00 & 0 & 0 & 0 & 0 & 0 & 0 & 0 & 0 & 0 & 0 & 0 & 0 & 0 & 0 & \\
\hline 24 & Korea, Rep. of & 0 & 00 & 00 & 0 & 0 & 00 & 0 & 0 & 0 & 0 & 0 & 0 & 0 & 0 & 0 & 0 & 0 & 0 & 0 & 0 & 0 \\
\hline
\end{tabular}


Notice that countries are ranked according to the official HDI values (from highest $=1$ to lowest $=24$ ). Thus, whenever we find (in Tables 3 and 4 ) a ' 1 ' below the diagonal, we have a 'rank reversal,' i.e., a country with a worse HDI rank which, using our robust method, dominates a country with a better HDI rank. Whenever we find a ' 0 ' above the diagonal, we have a 'disputable ranking', i.e., a country with a worse HDI rank that, given the perspective of modelling uncertainty that we uphold, cannot be compared decisively to a country with a better HDI rank. From inspection of the tables, rank reversals do not occur. However, many 'disputable HDI rankings' exist: almost $75 \%$ of all possible pairwise comparisons for the strong criterion. To recall, this means that if there is disagreement about the appropriate weighting vector, three out of four times there is either no (generalized Lorenz) dominance relation between the two countries, or, the finding that country $\alpha$ outperforms country $\beta$ may be reversed, conditional upon which weighting vector (taken from $W^{p}$ ) is actually used. Such disputable rankings occur in $50 \%$ of the cases for the weak criterion. Or stated verbally: we seek at least one possible weighting scheme for which one country (generalized Lorenz) dominates another, while at the same time the reverse relation does not hold, but in half of the cases this weighting scheme cannot be found. Moreover, a large part (i.e., 25\%) of the remaining undisputable cases is essentially trivial, as they would also pass the unanimity test (i.e., the dominating country achieves a higher score in each dimension separately). Thus, if we disregard the uncontroversial unanimity rankings, none of the HDI rankings are robust according to the strong dominance criterion $\succ_{*}^{1 / 4}$, while only $25 \%$ is considered robust when using the weak version. ${ }^{12}$

There is also another sense in which the HDI's complete ranking (i.e., its 'hitparade nature') can be questioned. If we zoom in on the strong criterion, some countries never dominate another country (Ireland, Luxembourg, Italy, Greece and the Republic of Korea), while others are never dominated by another country (Norway, Sweden, Australia, Canada, the Netherlands, Iceland, Japan, Switzerland and Luxembourg). Notice that one of the OECD countries is developed 'by default.' More precisely, Luxembourg never dominates another country (due to its low school enrollment rate), but is also never dominated (due to its high GDP per capita). Other countries - the United States, Japan and Ireland - are 'almost' developed 'by default' (dominated by at most one country and dominating at most one country), but for different reasons. More specifically, while the United States and Ireland attain a high GDP per capita, but a moderate life expectancy and school performance, Japan achieves a high life expectancy and a poor school performance. Diverging circumstances or policy choices may lead to more unequal (weighted) scores. In contrast to the HDI, our methodology is sensitive to such inequality and thus puts such a less balanced development at a disadvantage.

Now, let us focus on the weak criterion. Using this conservative criterion, we retain only a single country (Republic of Korea) that never dominates another country, while some other countries (Norway, Sweden, Australia and Luxembourg) are never dominated. Also note that the Republic of Korea is now dominated by all other

\footnotetext{
${ }^{12}$ Recalling our discussion in Section 3, this means that for the OECD countries the dominance table according to $\succ_{*}^{1 / 4}$ corresponds with the unanimity ranking based on $\succ_{*}^{0}$.
} 


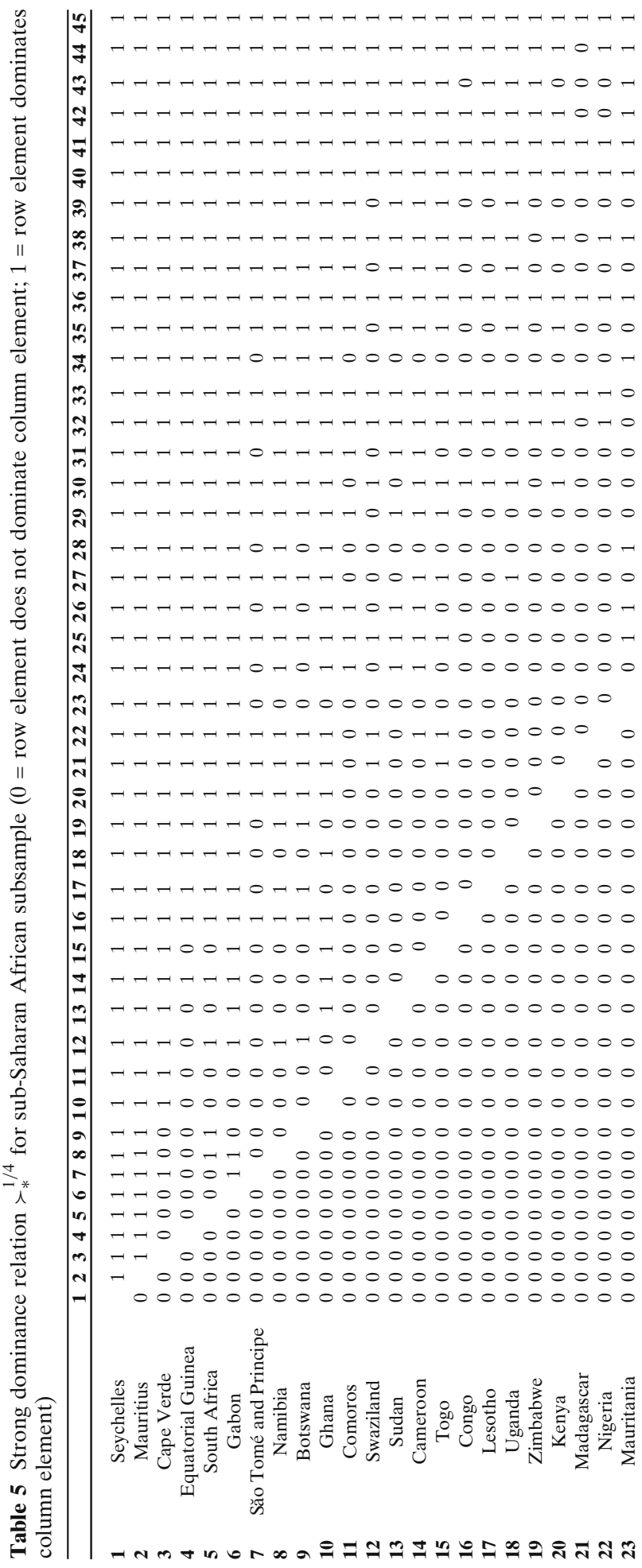


$4 \rightarrow-7-7 \rightarrow-0 \rightarrow-7 \rightarrow-7-7-7000$

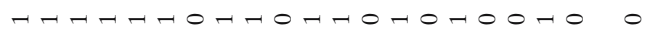

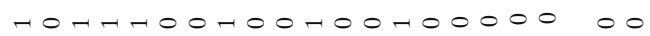
-

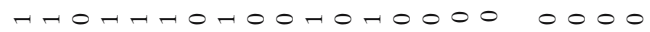

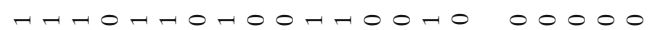
$000-000-0000000000000$ H-HOH- H H $0000000-0000000000000$ 000-1000t0000 000000000 $00000-1000000000000000$ 000000000000000000000 $000-00-00$ 000000000000 $000-00000000000000000$ 000000000000000000000 000000 000000000000000 000000000000000000000 00000000000000000000 000000000000000000000 r - 00000000000000000000 000000000000000000000 0000000000000000000000 0000000000000000000000 0000000000000000000000 0000000000000000000000 0000000000000000000000 0000000000000000000000 0000000000000000000000 0000000000000000000000 0000000000000000000000 0000000000000000000000 0000000000000000000000 0000000000000000000000 0000000000000000000000 0000000000000000000000 0000000000000000000000 0000000000000000000000 0000000000000000000000 0000000000000000000000 0000000000000000000000 0000000000000000000000 0000000000000000000000 0000000000000000000000 0000000000000000000000

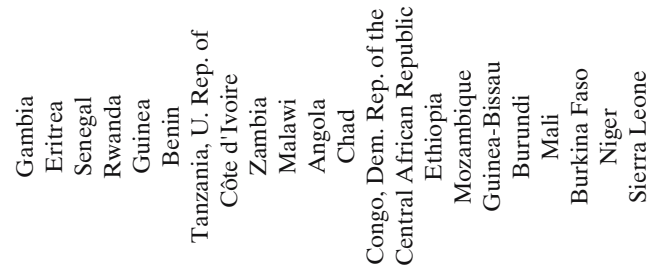

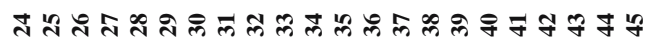




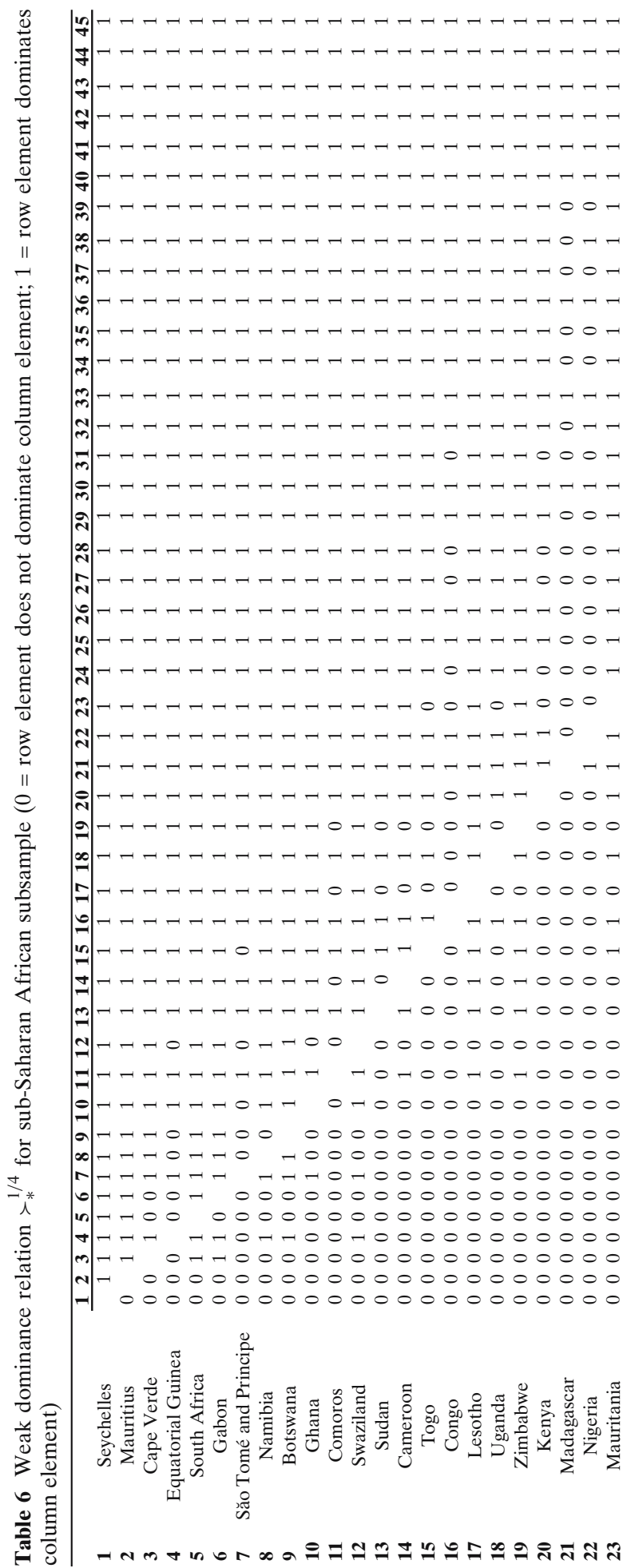




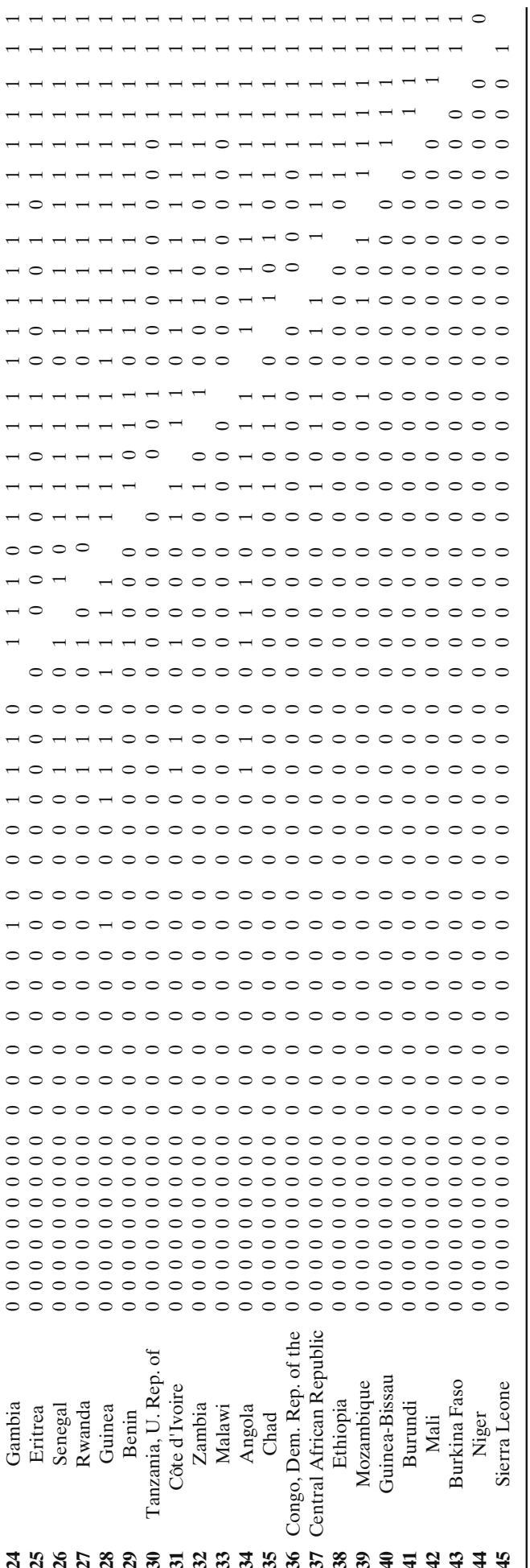

ปี่ 
countries. Recall that the weak criterion is much more flexible than the strong one: it allows countries to put more weight on their best achievement over the different dimensions. Therefore, the United States, Ireland and Japan are able to dominate other countries (and are dominated by others). Only Luxembourg remains (almost) developed 'by default.'

Finally, we look at the 45 sub-Saharan African countries in our sample. In Tables 5 and 6 we report the dominance tables for $\succ_{*}^{1 / 4}$ and $\succ^{1 / 4}$. These countries are again ranked according to the HDI (from highest $=1$ to lowest $=45$ ).

Once more, we do not find rank reversals for the strong criterion, but now there are 81 rank reversals for the weak criterion. Let us zoom in on the extreme cases, viz. countries weakly dominating other countries, while the latter are nonetheless ranked at least 10 positions higher according to the HDI (for the subgroup of subSaharan African countries). Although Guinea has a worse school performance, it is able to dominate Congo, because the weak criterion allows it to pick out one specific weighting scheme so as to put sufficient weight on its best achievement (relative to Congo), namely its GDP per capita figure. Apparently, the opposite relationship does not hold, i.e., Congo cannot put sufficient weight on its best achievement (relative to Guinea) to outperform Guinea. The same mechanism (via a relatively high GDP per capita) allows (1) Angola to dominate both Madagascar and Nigeria and (2) Cote d'Ivoire to dominate Madagascar.

Although we find some rank reversals (according to the weak dominance criterion), there are less disputable rankings in this subset, i.e., fewer countries that are ranked by the HDI but which turn out to be non-comparable once disagreement has been introduced. More precisely, about 59 and $97 \%$ of all pairwise comparisons are considered robust by respectively the strong and the weak dominance criterion. But again, we should remark that $21 \%$ of all pairwise comparisons are due to unanimity. Thus, disregarding the uncontroverial unanimity rankings leaves us with $38 \%$ of all comparisons that are robust according to our strong criterion, while $75.6 \%$ are robust in terms of the weak criterion.

Finally, using the strong dominance criterion, the Seychelles are never dominated, while at the other end, Burkina Faso, Mali and Niger never dominate another country. Even stronger, the Seychelles succeed in dominating all other countries, while Niger is dominated by all other countries. Moving to the weak criterion, the Seychelles again are never dominated - as they dominate all other countries while Niger never dominates another country - as it is dominated by all other countries.

\subsection{Statistical robustness analysis of the HDI}

The above results for the OECD and sub-Saharan African subsamples demonstrate the usefulness of our method in descriptively assessing the robustness of pairwise dominance relationships. As a general conclusion, we may state that they question the robustness of the HDI as a ranking tool. Indeed, for both subsamples we obtain the result that a large part of the HDI country dominance relationships does not appear to be robust with respect to the strong outranking criterion; and a similar conclusion, albeit to a somewhat lesser extent, applies for the (more conservative) weak criterion. We now complement this descriptive assessment by a statistical investigation, which considers the full sample of 177 countries.

悬 Springer 
Table 7 Decomposition of the HDI ranking into robust and non-robust comparisons

\begin{tabular}{llllll}
\hline & \multirow{2}{*}{ Robust due to } & \multicolumn{3}{l}{ Non-robust due to } \\
\cline { 2 - 3 } \cline { 5 - 6 } & Unanimity (\%) & Non-unanimity (\%) & & Non-comparability (\%) & Rank reversals (\%) \\
\hline$\succ_{*}^{1 / 4}$ & 69.66 & 4.39 & 25.94 & 0.01 \\
$\succ^{1 / 4}$ & 69.66 & 23.44 & 1.70 & 5.19 \\
\hline
\end{tabular}

Before presenting the statistical results, we start with some general observations that allow for a rough assessment of the robustness of the HDI ranking. Obviously, the HDI ranking is complete and thus allows us to rank $100 \%$ of all possible pairwise country comparisons. Table 7 decomposes this percentage of pairwise comparisons into robust comparisons and non-robust comparisons (in columns), using the $\succ_{*}^{1 / 4}$ and $\succ^{1 / 4}$ dominance criteria (in rows) to check robustness.

The explanation of the table is as follows. If we focus on the strong criterion $\succ_{*}^{1 / 4}$, the percentage of robust comparisons is about $74 \%(=69.66+4.39 \%)$. Still, the bulk of these pairwise dominance relationships (namely, $69.66 \%$ ) is due to unanimity, i.e., a country which dominates another country by a higher (weighted) score in each dimension. Non-robust comparisons are mainly due to rankings which are judged non-comparable according to $\succ_{*}^{1 / 4}$, rather than rank reversals. More precisely, only two rank reversals took place: South Africa (resp. Indonesia) is more developed than Tajikistan (resp. Equatorial Guinea) according to $\succ_{*}^{1 / 4}$, while Tajikistan (resp. Equatorial Guinea) has a higher HDI rank. ${ }^{13}$ Using the weak criterion $\succ^{1 / 4}$, the picture is very different. $93.1 \%$ of all pairwise comparisons are robust and a significant part $(23.44 \%)$ is not due to unanimity. Thus, there are possible weighting schemes that corroborate the HDI ranking. This is mirrored by a serious decline in the number of non-decisive rankings (only $1.70 \%$ ). However, one also observes somewhat more rank reversals $(5.19 \%)$. To conclude, if we disregard the unanimity part - which are basically non-controversial rankings - the weak criterion seems to confirm the HDI ranking, while the strong criterion clearly disagrees with the HDI in the sense that it considers a significant part of countries as mutually incomparable. Recall however that, by construction, the weak criterion ultimately allows for assigning different weight vectors to different countries, so as to present each of them in its best possible perspective. While we believe that this criterion is justifiable in a setting characterized by uncertainty, we do point out that it is not even remotely supported by the current HDI construction methodology (in which both the aggregator and the weights are uniformly imposed on all countries).

We next want to obtain a more precise 'statistical' statement regarding the robustness of the HDI ranking, as well as of the UNDP's concomitant classification of the countries in human development groups. We proceed as follows. On the basis of the HDI ranking, the United Nations arranges countries into three groups, ranging from low over middle to high human development. We employ $\chi^{2}$ goodness-of-fit tests to investigate the extent to which the distribution of the robust dominance

\footnotetext{
${ }^{13}$ Actually, the rank reversal of Equatorial Guinea is quite probably due to a data problem: the UN reports a (tenfold?) high GDP figure for this country and also uses it in its calculation of the HDI rank.
} 
Table 8 Comparing $\succ_{*}^{1 / 4}$ and the United Nations' human development classification

\begin{tabular}{|c|c|c|c|c|c|c|}
\hline $\begin{array}{l}j \\
i\end{array}$ & $\#$ & & 1 & 2 & & 3 \\
\hline 1 & 55 & & 51.11 & 84.78 & & 100.00 \\
\hline 2 & 86 & & 0.00 & 48.04 & & 90.44 \\
\hline 3 & 36 & & 0.00 & 0.00 & & 36.67 \\
\hline With diagonals: & $\chi^{2}$ & $=$ & 1732.18 & $(p$ & $=$ & $0.000)$ \\
\hline Without diagonals: & $\chi^{2}$ & $=$ & 137.90 & $(p$ & $=$ & $0.000)$ \\
\hline
\end{tabular}

relationship over the different classes complies with the expected distribution under the null hypothesis that the HDI ranking/classification is effectively robust.

Table 8 presents the results for the HDI country classification using the strong dominance criterion $\succ_{*}^{1 / 4}$. The second column (with label '\#') contains the number of countries in each human development class. In the following columns, each cell $i j$ (row $i$ and column $j$ ) presents the number of times a country ranked by the UN in class $i$ dominates a country ranked in class $j$; this number is expressed as a percentage of the maximum number of pairwise comparisons possible (for classes $i$ and $j$ ). Moving from the lower left to the upper right corner, the percentages increase. This stands to reason: countries with a higher (lower) value for the original HDI ranking are more likely to dominate (to be dominated by) others.

If the HDI ranking were a fully robust tool for ranking individual countries, then all cells on and above the diagonal in Table 8 would value $100 \%$. Hence, the $\chi^{2}$ tests that include the diagonal values in the table can be conceived as a (weak) check for robustness of the HDI country ranking. Next, robustness of the HDI classification only requires $100 \%$ in the cells above the diagonal, whence the robustness of this classification can be checked by excluding the diagonal values in the $\chi^{2}$ tests.

Table 8 reports values that are rather far below $100 \%$, not only on the diagonal (even as low as $36.67 \%$ ) but also above the diagonal (as low as $84.04 \%$ ). The $\chi^{2}$ tests confirm this impression. When including the diagonal entries, we strongly reject the hypothesis that the HDI is a robust ranking tool. When excluding the diagonal cells, which means that we consider robustness of the HDI classification, the test statistic decreases sharply, but the value remains improbable under the null hypothesis of a strongly robust HDI classification.

Table 9 Comparing $\succ_{*}^{1 / 4}$ and the United Nations' human development classification

\begin{tabular}{|c|c|c|c|c|c|c|}
\hline $\begin{array}{l}j \\
i\end{array}$ & \# & & 1 & 2 & & 3 \\
\hline 1 & 55 & & 87.81 & 99.22 & & 100.00 \\
\hline 2 & 86 & & 0.76 & 99.53 & & 98.61 \\
\hline 3 & 36 & & 0.00 & 0.94 & & 91.75 \\
\hline With diagonals: & $\chi^{2}$ & $=$ & 27.32 & $(p$ & $=$ & $0.000)$ \\
\hline Without diagonals: & $\chi^{2}$ & $=$ & 0.89 & $(p$ & $=$ & $0.642)$ \\
\hline
\end{tabular}


This first assessment casts serious doubt on the robustness of the HDI results. Yet, it is based on the rather stringent dominance criterion $\succ_{*}^{1 / 4}$, and may be conceived as too harsh. Table 9 uses the milder criterion $\succ^{1 / 4}$ as a base of comparison. Notice that the percentages on and above the diagonal are now much closer to $100 \%$. The results of the $\chi^{2}$ tests are mixed: while they reject robustness of the HDI ranking (see the results that include the diagonal values), they support robustness of the HDI classification (see the results that exclude the diagonals).

Tables 8 and 9 partly confirm the rough picture sketched in Table 7 . Using the strong dominance criterion $\succ_{*}^{1 / 4}$ to test the robustness of both the HDI country ranking and the country classification leads to rejection. However, the weak dominance criterion $\succ^{1 / 4}$ is milder: although the complete HDI ranking is not robust, at least as a classification device it can stand the robustness test. Therefore, as a main conclusion, we may state that our analysis suggests that the (incomplete) HDI classification is reasonably robust, while the opposite holds for the (complete) HDI country ranking. ${ }^{14}$

\section{Conclusion}

We have presented a robust approach to rank alternatives (e.g., different countries), when there are multiple relevant performance dimensions (e.g., the different dimensions of human development). First, we suggested a formal weighting procedure that seeks to express the usual controversies associated with this step in composite indicator building. Basically, this is achieved by simultaneously incorporating a wide range of possible weighting schemes in the outranking tests. Second, we proposed a generalized Lorenz dominance criterion for aggregating the different performance dimensions, which effectively obtains a ranking criterion that is consistent with the whole class of increasing, S-concave indices. Third, we proposed a weak as well as a strong dominance criterion, based on the previous weighting/aggregation step. Both versions can be implemented via linear programming, which is convenient from a practical point of view.

Our assessment of the Human Development Index illustrates the practical usefulness of the procedure. In particular, our application has focused on testing the robustness of (1) the United Nations' HDI itself as a tool for ranking individual countries and (2) the corresponding country classification, which is based on the HDI, into low, middle or high development. We found that the HDI classification (i.e., essentially an incomplete country ranking) may be conceived as reasonably robust, while the opposite holds for the (complete) HDI ranking. Specifically, we have shown that there are many cases in which the HDI country ranking may be called 'disputable,' which means that two countries turn out to be incomparable or are subject to a rank reversal when accounting for disagreement regarding the appropriate evaluation scheme. In fact, such disputable rankings are mainly situated within the HDI classes rather than between countries of different classes, which explains the more favorable testing results for the HDI classification. Of course these

\footnotetext{
${ }^{14}$ Of course, the above findings are contingent on the specific disagreement level we have started from. Thus, it is certainly worth mentioning that our (weak) robustness test cannot reject robustness of the HDI ranking on the basis of the weak criterion $\succ^{0}$.
} 
findings can be criticized, in that our weighting/aggregation methodology and the one actually used by UNDP are quite different. For example, the fact remains that we have used GDP per capita, whereas the HDI is (not uncontroversially) built on its logarithmic value. Note however that this is at least partly neutralized by the very fact that we allow for a broad range of implicit trade-off values. The same holds for the aggregation procedure we proposed: it admittedly cannot produce HDI-like index numbers, but the rationale of this 'shortcoming' is precisely that we want to check several possible indices simultaneously. Taken as such, the proposed methodology is of direct instrumental value: it seems more plausible to found comparisons openly on a broad consensus (i.e., on the use of a family of indices, and a particular set of weights), rather than on narrowly defined (and clearly disputable) modelling options. Finally, and more importantly, even if our results with regard to the HDI are deemed only partially substantive, our application still makes the general demonstration that the proposed methodology may be instrumental for a descriptive as well as a statistical robustness investigation of existing country rankings/classifications when multiple performance dimensions are relevant.

An interesting avenue for further research consists in endogenously defining a classification of countries on the basis of the (weakly or strongly) robust outranking criteria as they have been defined in this study. Specifically, this would boil down to conceiving a country classification such that each country in a higher class (resp. weakly or strongly) robustly dominates each country in a lower class, while the opposite never occurs. Such an endogenous classification exercise is similar in spirit to Noorbakhsh [19]. Another interesting question is whether the gap between strong and weak dominance-between 'all' and 'at least one' allowable weighting scheme(s) supporting a country—can be filled, e.g., by using a criterion that tells us what percentage of all possible weighting schemes favours one country over another.

Acknowledgements We thank three anonymous referees for helpful comments. In addition, we are grateful to Isabel Günther, Serge Kolm and other participants of the "First Meeting of the Society for the Study of Economic Inequality (ECINEQ)" (Palma de Mallorca, July, 2005) for useful comments and suggestions. This paper is an offshoot of the KEI-project (contract $n^{\circ} 502529$ ) that is part of priority 8 of the policy orientated research under the European Commission's Sixth Framework Programme (see http://kei.publicstatistics.net/).

\section{Appendix A: Proofs}

\section{Proof of Proposition 2A}

Combining (part (1) of) Definition 1 and Proposition 2, (1) ${ }_{*}^{p}$ holds if and only if

$$
\sum_{k=1}^{j}\left(w_{k} x_{k}\right)_{\langle k\rangle} \geq \sum_{k=1}^{j}\left(w_{k} y_{k}\right)_{\langle k\rangle} \text { for all } \mathbf{w} \in W^{p} \text { and for all } j \in J .
$$


Using the definition of $S_{j}$, we have (for any $\mathbf{a} \in \mathbb{R}^{n}$ ) that $\sum_{k=1}^{j} a_{\langle k\rangle}=$ $\min _{K \in S_{j}(J)}\left(\sum_{k \in K} a_{k}\right)$; thus we can rewrite condition (1) as

$$
\min _{K \in S_{j}(J)}\left(\sum_{k \in K} w_{k} x_{k}\right)-\min _{L \in S_{j}(J)}\left(\sum_{\ell \in L} w_{\ell} y_{\ell}\right) \geq 0 \text { for all } \mathbf{w} \in W^{p} \text { and for all } j \in J .
$$

Finally, using min-operators and manipulating the expression (basically, using $\min f=-\max (-f)$ and permuting max-operators), we get

$$
\begin{aligned}
(1)_{*}^{p} \text { holds } & \Leftrightarrow \min _{\mathbf{w} \in W^{p}} \min _{j \in J}\left[\min _{K \in S_{j}(J)}\left(\sum_{k \in K} w_{k} x_{k}\right)-\min _{L \in S_{j}(J)}\left(\sum_{\ell \in L} w_{\ell} y_{\ell}\right)\right] \geq 0 . \\
& \Leftrightarrow \max _{\mathbf{w} \in W^{p}} \max _{j \in J}\left[\min _{L \in S_{j}(J)}\left(\sum_{\ell \in L} w_{\ell} y_{\ell}\right)-\min _{K \in S_{j}(J)}\left(\sum_{k \in K} w_{k} x_{k}\right)\right] \leq 0 \\
& \Leftrightarrow \max _{\mathbf{w} \in W^{p}} \max _{j \in J} \max _{K \in S_{j}(J)}\left[\min _{L \in S_{j}(J)}\left(\sum_{\ell \in L} w_{\ell} y_{\ell}\right)-\sum_{k \in K} w_{k} x_{k}\right] \leq 0 \\
& \Leftrightarrow \max _{j \in J} \max _{K \in S_{j}(J)} \max _{\mathbf{w} \in W^{p}}\left[\min _{L \in S_{j}(J)}\left(\sum_{\ell \in L} w_{\ell} y_{\ell}\right)-\sum_{k \in K} w_{k} x_{k}\right] \leq 0,
\end{aligned}
$$

as required. In the same vein, we can start from (2) ${ }_{*}^{p}$ to get

$$
\begin{aligned}
(2)_{*}^{p} \text { holds } & \Leftrightarrow \max _{\mathbf{w} \in W^{p}} \max _{j \in J}\left[\min _{K \in S_{j}(J)}\left(\sum_{k \in K} w_{k} x_{k}\right)-\min _{L \in S_{j}(J)}\left(\sum_{\ell \in L} w_{\ell} y_{\ell}\right)\right]>0 \\
& \Leftrightarrow \min _{\mathbf{w} \in W^{p}} \min _{j \in J}\left[\min _{L \in S_{j}(J)}\left(\sum_{\ell \in L} w_{\ell} y_{\ell}\right)-\min _{K \in S_{j}(J)}\left(\sum_{k \in K} w_{k} x_{k}\right)\right]<0 .
\end{aligned}
$$

Compare the last Eq. 4 with the first Eq. 2: $x$ and $y$ have changed place and the inequality sign is opposite (strict and the other way around). In the same way as for (1) ${ }_{*}^{p}$ we can manipulate the expression to end up with Eq. 3, but with the opposite inequality sign and permuting $x$ and $y$ :

$$
\text { (2) }{ }_{*}^{p} \text { holds } \Leftrightarrow \max _{j \in J} \max _{L \in S_{j}(J)} \max _{\mathbf{w} \in W^{p}}\left[\min _{K \in S_{j}(J)}\left(\sum_{k \in K} w_{k} x_{k}\right)-\sum_{\ell \in L} w_{\ell} y_{\ell}\right]>0 .
$$

\section{Proof of Proposition 2B}

We must show that $\varepsilon_{*}^{p}(\mathbf{a}, \mathbf{b})$ (as defined in Proposition 2B) equals

$$
\max _{j \in J} \max _{K \in S_{j}(J)} \max _{\mathbf{w} \in W^{p}}\left(\min _{L \in S_{j}(J)}\left(\sum_{\ell \in L} w_{\ell} b_{\ell}\right)-\sum_{k \in K} w_{k} a_{k}\right) .
$$

At the optimum of the linear program, we must have that $\alpha=\beta-\sum_{k \in K} w_{k} a_{k}$ and $\beta=\min _{L \in S_{i}(J)}\left(\sum_{\ell \in L} w_{\ell} b_{\ell}\right)$; otherwise, it would be possible to find a better solution. 
Combining both leads to the desired result, i.e, at the optimum, we must have that

$$
\alpha=\left(\min _{L \in S_{j}(J)}\left(\sum_{\ell \in L} w_{\ell} b_{\ell}\right)-\sum_{k \in K} w_{k} a_{k}\right)
$$

Proof of Proposition 3A

In the same way as for Proposition 2A, we get

$$
\begin{aligned}
(1)^{p} \text { holds } & \Leftrightarrow \max _{\mathbf{w} \in W^{p}} \min _{j \in J}\left[\min _{K \in S_{j}(J)}\left(\sum_{k \in K} w_{k} x_{k}\right)-\min _{L \in S_{j}(J)}\left(\sum_{\ell \in L} w_{\ell} y_{\ell}\right)\right] \geq 0 \\
& \Leftrightarrow \min _{\mathbf{w} \in W^{p}} \max _{j \in J}\left[\min _{L \in S_{j}(J)}\left(\sum_{\ell \in L} w_{\ell} y_{\ell}\right)-\min _{K \in S_{j}(J)}\left(\sum_{k \in K} w_{k} x_{k}\right)\right] \leq 0 .
\end{aligned}
$$

Observing that

$$
\min _{L \in S_{j}(J)}\left(\sum_{\ell \in L} w_{\ell} y_{\ell}\right)-\min _{K \in S_{j}(J)}\left(\sum_{k \in K} w_{k} x_{k}\right)=\min _{\pi \in \Pi(J)}\left[\sum_{\ell=1}^{j} w_{\pi(\ell)} y_{\pi(\ell)}-\min _{K \in S_{j}(J)}\left(\sum_{k \in K} w_{k} x_{k}\right)\right],
$$

we can rewrite Eq. 5 as

$$
\begin{aligned}
& \Leftrightarrow \min _{\mathbf{w} \in W^{p}} \max _{j \in J} \min _{\pi \in \Pi(J)}\left[\sum_{\ell=1}^{j} w_{\pi(\ell)} y_{\pi(\ell)}-\min _{K \in S_{j}(J)}\left(\sum_{k \in K} w_{k} x_{k}\right)\right] \leq 0 \\
& \Leftrightarrow \max _{j \in J} \min _{\pi \in \Pi(J)} \min _{\mathbf{w} \in W^{p}}\left[\sum_{\ell=1}^{j} w_{\pi(\ell)} y_{\pi(\ell)}-\min _{K \in S_{j}(J)}\left(\sum_{k \in K} w_{k} x_{k}\right)\right] \leq 0 .
\end{aligned}
$$

The proof for $(2)^{p}$ is again similar (as in the proof of Proposition 2A, it boils down to permuting $x$ and $y$ and changing the inequality sign).

Proof of Proposition 3B

The proof is analogous to the proof of Proposition 2B.

\section{Appendix B: Summary information}

For the criteria $\succ_{*}^{0}$ (see 'strong dominance') and $\succ^{0}$ (see 'weak dominance') we tabulate, for each individual country, the number of observations that is (robustly) dominated by that country and the number of observations that is dominating the country. We rank the countries for each criterion on the basis of a 'net dominance' metric, which is calculated as the number of dominated minus the number of dominating observations. We stress the illustrative nature of these summarizing results; other ranking procedures are equally possible. Given the specific orientation of the current paper, our main focus is on the pairwise dominance relationships. More detailed (country-specific) pairwise dominance information is given in Tables 3-6; additional results are available from the authors upon simple request. 
Strong dominance

\begin{tabular}{|c|c|c|c|c|}
\hline Rank & Country & $\begin{array}{l}\text { Number } \\
\text { dominated } \\
\text { by country }\end{array}$ & $\begin{array}{l}\text { Number } \\
\text { dominating } \\
\text { country }\end{array}$ & $\begin{array}{l}\text { Net } \\
\text { dominance }\end{array}$ \\
\hline 1 & Australia & 162 & 0 & 162 \\
\hline 2 & Norway & 161 & 0 & 161 \\
\hline 3 & Canada & 159 & 0 & 159 \\
\hline 4 & Belgium & 159 & 1 & 158 \\
\hline 5 & Sweden & 157 & 0 & 157 \\
\hline 6 & Netherlands & 155 & 0 & 155 \\
\hline 7 & Iceland & 153 & 0 & 153 \\
\hline 8 & United Kingdom & 151 & 2 & 149 \\
\hline 8 & Austria & 151 & 2 & 149 \\
\hline 10 & Switzerland & 148 & 0 & 148 \\
\hline 10 & France & 151 & 3 & 148 \\
\hline 10 & New Zealand & 151 & 3 & 148 \\
\hline 10 & Spain & 150 & 2 & 148 \\
\hline 14 & Finland & 149 & 2 & 147 \\
\hline 15 & Denmark & 147 & 1 & 146 \\
\hline 16 & United States & 145 & 1 & 144 \\
\hline 17 & Ireland & 144 & 1 & 143 \\
\hline 18 & Japan & 142 & 0 & 142 \\
\hline 19 & Germany & 144 & 8 & 136 \\
\hline 20 & Luxembourg & 131 & 0 & 131 \\
\hline 20 & Israel & 137 & 6 & 131 \\
\hline 22 & Italy & 138 & 8 & 130 \\
\hline 23 & Portugal & 139 & 10 & 129 \\
\hline 24 & Greece & 136 & 13 & 123 \\
\hline 25 & Slovenia & 138 & 16 & 122 \\
\hline 26 & Korea, Rep. of & 133 & 13 & 120 \\
\hline 27 & Barbados & 132 & 13 & 119 \\
\hline 28 & Singapore & 127 & 15 & 112 \\
\hline 29 & Argentina & 124 & 19 & 105 \\
\hline 30 & Hong Kong, China (SAR) & 100 & 1 & 99 \\
\hline 30 & Poland & 119 & 20 & 99 \\
\hline 32 & Cyprus & 116 & 18 & 98 \\
\hline 33 & Czech Republic & 120 & 25 & 95 \\
\hline 34 & Estonia & 101 & 9 & 92 \\
\hline 35 & Malta & 106 & 15 & 91 \\
\hline 36 & Lithuania & 108 & 21 & 87 \\
\hline 36 & Uruguay & 112 & 25 & 87 \\
\hline 38 & Chile & 109 & 27 & 82 \\
\hline 39 & Slovakia & 109 & 29 & 80 \\
\hline 40 & Brunei Darussalam & 101 & 23 & 78 \\
\hline 40 & Saint Kitts and Nevis & 88 & 10 & 78 \\
\hline 42 & Croatia & 107 & 30 & 77 \\
\hline 43 & Hungary & 99 & 23 & 76 \\
\hline
\end{tabular}


L. Cherchye, et al.

\begin{tabular}{|c|c|c|c|c|}
\hline Rank & Country & $\begin{array}{l}\text { Number } \\
\text { dominated } \\
\text { by country }\end{array}$ & $\begin{array}{l}\text { Number } \\
\text { dominating } \\
\text { country }\end{array}$ & $\begin{array}{l}\text { Net } \\
\text { dominance }\end{array}$ \\
\hline 44 & Seychelles & 101 & 26 & 75 \\
\hline 45 & Costa Rica & 93 & 22 & 71 \\
\hline 46 & Latvia & 94 & 26 & 68 \\
\hline 47 & Cuba & 82 & 24 & 58 \\
\hline 48 & Bahrain & 87 & 30 & 57 \\
\hline 49 & Qatar & 74 & 23 & 57 \\
\hline 50 & Bulgaria & 84 & 34 & 50 \\
\hline 51 & Kuwait & 76 & 27 & 49 \\
\hline 52 & Belarus & 73 & 27 & 46 \\
\hline 53 & Libyan Arab Jamahiriya & 83 & 40 & 43 \\
\hline 53 & Macedonia, TFYR & 80 & 37 & 43 \\
\hline 55 & Mexico & 78 & 39 & 39 \\
\hline 55 & Trinidad and Tobago & 79 & 40 & 39 \\
\hline 57 & Panama & 74 & 36 & 38 \\
\hline 58 & United Arab Emirates & 58 & 21 & 37 \\
\hline 59 & Albania & 73 & 37 & 36 \\
\hline 60 & Ukraine & 68 & 33 & 35 \\
\hline 62 & Russian Federation & 61 & 27 & 34 \\
\hline 62 & Saint Lucia & 72 & 38 & 34 \\
\hline 64 & Malaysia & 72 & 39 & 33 \\
\hline 64 & Suriname & 74 & 41 & 33 \\
\hline 66 & Bahamas & 59 & 28 & 31 \\
\hline 67 & Bosnia and Herzegovina & 69 & 39 & 30 \\
\hline 68 & Tonga & 62 & 34 & 28 \\
\hline 69 & Venezuela & 68 & 41 & 27 \\
\hline 70 & Mauritius & 66 & 40 & 26 \\
\hline 70 & Romania & 68 & 42 & 26 \\
\hline 70 & Jamaica & 60 & 34 & 26 \\
\hline 73 & Samoa (Western) & 66 & 43 & 33 \\
\hline 74 & Armenia & 58 & 36 & 22 \\
\hline 75 & Colombia & 67 & 46 & 21 \\
\hline 76 & Saint Vincent and the Grenadines & 60 & 41 & 19 \\
\hline 77 & Kazakhstan & 54 & 36 & 18 \\
\hline 78 & Turkmenistan & 54 & 37 & 17 \\
\hline 79 & Azerbaijan & 57 & 41 & 16 \\
\hline 80 & Brazil & 57 & 42 & 15 \\
\hline 80 & Philippines & 62 & 47 & 15 \\
\hline 80 & Maldives & 55 & 40 & 15 \\
\hline 83 & Lebanon & 61 & 47 & 14 \\
\hline 84 & Oman & 49 & 37 & 12 \\
\hline 84 & Thailand & 61 & 49 & 12 \\
\hline 86 & Saudi Arabia & 49 & 38 & 11 \\
\hline 86 & Dominica & 58 & 47 & 11 \\
\hline 86 & Georgia & 48 & 37 & 11 \\
\hline
\end{tabular}




\begin{tabular}{|c|c|c|c|c|}
\hline Rank & Country & $\begin{array}{l}\text { Number } \\
\text { dominated } \\
\text { by country }\end{array}$ & $\begin{array}{l}\text { Number } \\
\text { dominating } \\
\text { country }\end{array}$ & $\begin{array}{l}\text { Net } \\
\text { dominance }\end{array}$ \\
\hline 89 & Jordan & 60 & 53 & 7 \\
\hline 90 & Turkey & 62 & 56 & 6 \\
\hline 90 & Tunisia & 53 & 47 & 6 \\
\hline 92 & Fiji & 59 & 54 & 5 \\
\hline 92 & Paraguay & 61 & 56 & 5 \\
\hline 94 & Peru & 60 & 56 & 4 \\
\hline 95 & Sri Lanka & 56 & 53 & 3 \\
\hline 96 & Belize & 56 & 55 & 1 \\
\hline 96 & Iran, Islamic Rep. of & 56 & 55 & 1 \\
\hline 96 & Occupied Palestinian Territories & 48 & 47 & 1 \\
\hline 99 & China & 60 & 60 & 0 \\
\hline 100 & Grenada & 52 & 53 & -1 \\
\hline 101 & Guyana & 48 & 50 & -2 \\
\hline 102 & Ecuador & 56 & 59 & -3 \\
\hline 103 & Dominican Republic & 54 & 58 & -4 \\
\hline 103 & Uzbekistan & 33 & 37 & -4 \\
\hline 105 & Kyrgyzstan & 30 & 38 & -8 \\
\hline 106 & El Salvador & 54 & 65 & -11 \\
\hline 107 & Syrian Arab Republic & 50 & 63 & -13 \\
\hline 108 & Cape Verde & 54 & 69 & -15 \\
\hline 109 & South Africa & 27 & 45 & -18 \\
\hline 110 & Bolivia & 47 & 67 & -20 \\
\hline 111 & Algeria & 47 & 69 & -22 \\
\hline 112 & Mongolia & 33 & 56 & -23 \\
\hline 113 & Tajikistan & 16 & 43 & -27 \\
\hline 114 & Gabon & 34 & 67 & -33 \\
\hline 115 & Viet Nam & 46 & 80 & -34 \\
\hline 116 & Moldova, Rep. of & 26 & 62 & -36 \\
\hline 117 & Indonesia & 49 & 86 & -37 \\
\hline 118 & Botswana & 12 & 56 & -44 \\
\hline 119 & Honduras & 45 & 91 & -46 \\
\hline 120 & Nicaragua & 44 & 91 & -47 \\
\hline 121 & Namibia & 16 & 69 & -53 \\
\hline 122 & Egypt & 36 & 90 & -54 \\
\hline 123 & Guatemala & 39 & 97 & -58 \\
\hline 124 & Sao Tome and Principe & 24 & 83 & -59 \\
\hline 125 & Morocco & 28 & 91 & -63 \\
\hline 126 & Equatorial Guinea & 23 & 95 & -72 \\
\hline 127 & Solomon Islands & 24 & 100 & -76 \\
\hline 128 & India & 29 & 107 & -78 \\
\hline 129 & Vanuatu & 13 & 96 & -83 \\
\hline 130 & Cambodia & 28 & 112 & -84 \\
\hline 130 & Ghana & 29 & 113 & -84 \\
\hline 132 & Swaziland & 2 & 92 & -90 \\
\hline
\end{tabular}


L. Cherchye, et al.

\begin{tabular}{|c|c|c|c|c|}
\hline Rank & Country & $\begin{array}{l}\text { Number } \\
\text { dominated } \\
\text { by country }\end{array}$ & $\begin{array}{l}\text { Number } \\
\text { dominating } \\
\text { country }\end{array}$ & $\begin{array}{l}\text { Net } \\
\text { dominance }\end{array}$ \\
\hline 133 & Papua New Guinea & 22 & 114 & -92 \\
\hline 134 & Lao People's Dem. Rep. & 22 & 116 & -94 \\
\hline 134 & Zimbabwe & 1 & 95 & -94 \\
\hline 136 & Myanmar & 16 & 113 & -97 \\
\hline 136 & Lesotho & 2 & 99 & -97 \\
\hline 138 & Comoros & 19 & 117 & -98 \\
\hline 139 & Bhutan & 16 & 116 & -100 \\
\hline 140 & Sudan & 17 & 120 & -103 \\
\hline 141 & Cameroon & 14 & 118 & -104 \\
\hline 142 & Bangladesh & 13 & 118 & -105 \\
\hline 143 & Uganda & 12 & 118 & -106 \\
\hline 144 & Kenya & 8 & 115 & -107 \\
\hline 145 & Nepal & 12 & 122 & -110 \\
\hline 145 & Togo & 12 & 122 & -110 \\
\hline 145 & Congo & 9 & 119 & -110 \\
\hline 148 & Pakistan & 7 & 118 & -111 \\
\hline 148 & Mauritania & 8 & 119 & -111 \\
\hline 150 & Djibouti & 10 & 123 & -113 \\
\hline 151 & Haiti & 12 & 126 & -114 \\
\hline 152 & Yemen & 5 & 124 & -119 \\
\hline 152 & Guinea & 3 & 122 & -119 \\
\hline 154 & Nigeria & 6 & 126 & -120 \\
\hline 154 & Gambia & 7 & 127 & -120 \\
\hline 156 & Madagascar & 4 & 126 & -122 \\
\hline 157 & Timor-Leste & 0 & 124 & -124 \\
\hline 158 & Angola & 0 & 125 & -125 \\
\hline 159 & Benin & 6 & 132 & -126 \\
\hline 160 & Eritrea & 5 & 132 & -127 \\
\hline 160 & Rwanda & 2 & 129 & -127 \\
\hline 162 & Senegal & 4 & 132 & -128 \\
\hline 162 & Malawi & 1 & 129 & -128 \\
\hline 164 & Zambia & 0 & 130 & -130 \\
\hline 165 & Côte d'lvoire & 4 & 135 & -131 \\
\hline 166 & Tanzania, U. Rep. of & 1 & 134 & -133 \\
\hline 167 & Central African Republic & 1 & 142 & -141 \\
\hline 168 & Congo, Dem. Rep. of the & 2 & 144 & -142 \\
\hline 168 & Mozambique & 1 & 143 & -142 \\
\hline 170 & Chad & 1 & 144 & -143 \\
\hline 171 & Mali & 1 & 145 & -144 \\
\hline 171 & Burkina Faso & 0 & 144 & -144 \\
\hline 173 & Ethiopia & 2 & 150 & -148 \\
\hline 174 & Burundi & 1 & 151 & -150 \\
\hline 175 & Niger & 0 & 151 & -151 \\
\hline 176 & Guinea-Bissau & 0 & 155 & -155 \\
\hline 177 & Sierra Leone & 0 & 166 & -166 \\
\hline
\end{tabular}




\begin{tabular}{|c|c|c|c|c|}
\hline \multicolumn{5}{|c|}{ Weak dominance } \\
\hline Rank & Country & $\begin{array}{l}\text { Number } \\
\text { dominated } \\
\text { by country }\end{array}$ & $\begin{array}{l}\text { Number } \\
\text { dominating } \\
\text { country }\end{array}$ & $\begin{array}{l}\text { Net } \\
\text { dominance }\end{array}$ \\
\hline 1 & Luxembourg & 176 & 0 & 176 \\
\hline 2 & Norway & 175 & 1 & 174 \\
\hline 3 & Ireland & 173 & 2 & 171 \\
\hline 4 & United States & 172 & 3 & 169 \\
\hline 5 & Denmark & 172 & 4 & 168 \\
\hline 6 & Canada & 171 & 5 & 166 \\
\hline 7 & Iceland & 170 & 6 & 164 \\
\hline 8 & Switzerland & 168 & 7 & 161 \\
\hline 9 & Netherlands & 168 & 8 & 160 \\
\hline 10 & Australia & 167 & 9 & 158 \\
\hline 11 & Austria & 166 & 10 & 156 \\
\hline 12 & Belgium & 165 & 11 & 154 \\
\hline 13 & Sweden & 164 & 12 & 152 \\
\hline 14 & Japan & 162 & 13 & 149 \\
\hline 15 & France & 162 & 14 & 148 \\
\hline 16 & United Kingdom & 161 & 15 & 146 \\
\hline 17 & Finland & 160 & 16 & 144 \\
\hline 18 & Germany & 159 & 17 & 142 \\
\hline 19 & Italy & 157 & 18 & 139 \\
\hline 20 & Hong Kong, China (SAR) & 157 & 19 & 138 \\
\hline 21 & Singapore & 156 & 20 & 136 \\
\hline 22 & New Zealand & 155 & 21 & 134 \\
\hline 23 & Spain & 154 & 22 & 132 \\
\hline 24 & Israel & 153 & 23 & 130 \\
\hline 25 & Greece & 152 & 24 & 128 \\
\hline 26 & Slovenia & 151 & 25 & 126 \\
\hline 27 & Portugal & 150 & 26 & 124 \\
\hline 28 & Cyprus & 149 & 27 & 122 \\
\hline 29 & Brunei Darussalam & 148 & 28 & 120 \\
\hline 30 & United Arab Emirates & 147 & 29 & 118 \\
\hline 31 & Korea, Rep. of & 146 & 30 & 116 \\
\hline 32 & Malta & 145 & 31 & 114 \\
\hline 33 & Qatar & 144 & 32 & 112 \\
\hline 34 & Seychelles & 143 & 33 & 110 \\
\hline 35 & Barbados & 142 & 33 & 109 \\
\hline 36 & Czech Republic & 140 & 35 & 105 \\
\hline 37 & Bahrain & 140 & 36 & 104 \\
\hline 38 & Bahamas & 139 & 37 & 102 \\
\hline 39 & Kuwait & 138 & 38 & 100 \\
\hline 40 & Hungary & 137 & 39 & 98 \\
\hline 41 & Estonia & 136 & 40 & 96 \\
\hline 42 & Slovakia & 135 & 41 & 94 \\
\hline
\end{tabular}


L. Cherchye, et al.

\begin{tabular}{|c|c|c|c|c|}
\hline Rank & Country & $\begin{array}{l}\text { Number } \\
\text { dominated } \\
\text { by country }\end{array}$ & $\begin{array}{l}\text { Number } \\
\text { dominating } \\
\text { country }\end{array}$ & $\begin{array}{l}\text { Net } \\
\text { dominance }\end{array}$ \\
\hline 43 & Saint Kitts and Nevis & 134 & 42 & 92 \\
\hline 44 & Argentina & 132 & 43 & 89 \\
\hline 44 & Poland & 132 & 43 & 89 \\
\hline 46 & Lithuania & 129 & 45 & 84 \\
\hline 46 & Oman & 130 & 46 & 84 \\
\hline 48 & Chile & 128 & 47 & 81 \\
\hline 48 & Croatia & 128 & 47 & 81 \\
\hline 50 & Antigua and Barbuda & 127 & 49 & 78 \\
\hline 51 & Saudi Arabia & 126 & 50 & 76 \\
\hline 52 & Latvia & 125 & 51 & 74 \\
\hline 53 & Mauritius & 124 & 52 & 72 \\
\hline 54 & Costa Rica & 123 & 53 & 70 \\
\hline 55 & Trinidad and Tobago & 122 & 53 & 69 \\
\hline 56 & Mexico & 120 & 55 & 65 \\
\hline 57 & Uruguay & 119 & 56 & 63 \\
\hline 58 & Malaysia & 119 & 57 & 62 \\
\hline 59 & Russian Federation & 118 & 58 & 60 \\
\hline 60 & Libyan Arab Jamahiriya & 117 & 59 & 58 \\
\hline 61 & Brazil & 116 & 60 & 56 \\
\hline 62 & Bulgaria & 115 & 61 & 54 \\
\hline 63 & Tonga & 114 & 62 & 52 \\
\hline 64 & Thailand & 113 & 62 & 51 \\
\hline 65 & Macedonia, TFYR & 111 & 64 & 47 \\
\hline 66 & Suriname & 111 & 65 & 46 \\
\hline 67 & South Africa & 110 & 66 & 44 \\
\hline 68 & Romania & 109 & 67 & 42 \\
\hline 69 & Grenada & 107 & 68 & 39 \\
\hline 70 & Panama & 107 & 69 & 38 \\
\hline 71 & Bosnia and Herzegovina & 105 & 71 & 34 \\
\hline 71 & Colombia & 104 & 70 & 34 \\
\hline 73 & Belarus & 103 & 72 & 31 \\
\hline 74 & Cuba & 103 & 73 & 30 \\
\hline 74 & Dominican Republic & 102 & 72 & 30 \\
\hline 76 & Tunisia & 101 & 75 & 26 \\
\hline 77 & Kazakhstan & 100 & 76 & 24 \\
\hline 78 & Turkey & 99 & 77 & 22 \\
\hline 79 & Iran, Islamic Rep. of & 98 & 78 & 20 \\
\hline 80 & Somoa (Western) & 97 & 79 & 18 \\
\hline 81 & Venezuela & 96 & 80 & 16 \\
\hline 82 & Saint Lucia & 95 & 81 & 14 \\
\hline 83 & Fuji & 94 & 82 & 12 \\
\hline 84 & Belize & 93 & 83 & 10 \\
\hline 85 & Ukraine & 91 & 84 & 7 \\
\hline 86 & Albania & 91 & 85 & 6 \\
\hline
\end{tabular}




\begin{tabular}{|c|c|c|c|c|}
\hline Rank & Country & $\begin{array}{l}\text { Number } \\
\text { dominated } \\
\text { by country }\end{array}$ & $\begin{array}{l}\text { Number } \\
\text { dominating } \\
\text { country }\end{array}$ & $\begin{array}{l}\text { Net } \\
\text { dominance }\end{array}$ \\
\hline 87 & Saint Vincent and the Grenadines & 89 & 87 & 2 \\
\hline 87 & Dominica & 88 & 86 & 2 \\
\hline 89 & Peru & 88 & 88 & 0 \\
\hline 90 & Maldives & 87 & 89 & -2 \\
\hline 91 & Algeria & 86 & 90 & -4 \\
\hline 92 & Paraguay & 85 & 91 & -6 \\
\hline 93 & China & 83 & 91 & -8 \\
\hline 94 & Gabon & 83 & 93 & -10 \\
\hline 95 & Lebanon & 82 & 94 & -12 \\
\hline 96 & Cape Verde & 80 & 93 & -13 \\
\hline 97 & Turkmenistan & 81 & 95 & -14 \\
\hline 98 & Philippines & 78 & 96 & -18 \\
\hline 98 & El Salvador & 79 & 97 & -18 \\
\hline 100 & Jordan & 77 & 99 & -22 \\
\hline 101 & Botswana & 76 & 100 & -24 \\
\hline 102 & Jamaica & 75 & 101 & -26 \\
\hline 103 & Guyana & 74 & 102 & -28 \\
\hline 104 & Namibia & 73 & 103 & -30 \\
\hline 105 & Sri Lanka & 72 & 104 & -32 \\
\hline 106 & Armenia & 70 & 104 & -34 \\
\hline 106 & Ecuador & 71 & 105 & -34 \\
\hline 108 & Azerbaijan & 69 & 107 & -38 \\
\hline 109 & Syrian Arab Republic & 68 & 105 & -40 \\
\hline 110 & Guatemala & 67 & 109 & -42 \\
\hline 111 & Indonesia & 65 & 110 & -45 \\
\hline 112 & Egypt & 65 & 111 & -46 \\
\hline 113 & Georgia & 64 & 112 & -48 \\
\hline 114 & Occupied Palestinian Territories & 63 & 113 & -50 \\
\hline 115 & Morocco & 62 & 114 & -52 \\
\hline 116 & Bolivia & 61 & 115 & -54 \\
\hline 117 & Honduras & 60 & 116 & -56 \\
\hline 118 & Vietnam & 59 & 117 & -58 \\
\hline 119 & Nicaragua & 57 & 118 & -61 \\
\hline 120 & Swaziland & 57 & 119 & -62 \\
\hline 121 & Equatorial Guinea & 56 & 120 & -64 \\
\hline 122 & Uzbekistan & 54 & 121 & -67 \\
\hline 122 & Kyrgyzstan & 54 & 121 & -67 \\
\hline 124 & India & 53 & 122 & -69 \\
\hline 125 & Mongolia & 52 & 124 & -72 \\
\hline 126 & Moldova, Rep. of & 51 & 125 & -74 \\
\hline 127 & Vanuatu & 50 & 126 & -76 \\
\hline 128 & Ghana & 49 & 127 & -78 \\
\hline 129 & Cambodia & 48 & 128 & -80 \\
\hline 130 & Solomon Islands & 47 & 129 & -82 \\
\hline
\end{tabular}


L. Cherchye, et al.

\begin{tabular}{|c|c|c|c|c|}
\hline Rank & Country & $\begin{array}{l}\text { Number } \\
\text { dominated } \\
\text { by country }\end{array}$ & $\begin{array}{l}\text { Number } \\
\text { dominating } \\
\text { country }\end{array}$ & $\begin{array}{l}\text { Net } \\
\text { dominance }\end{array}$ \\
\hline 131 & Papua New Guinea & 46 & 130 & -84 \\
\hline 132 & Sao Tome and Principe & 45 & 131 & -86 \\
\hline 133 & Lesotho & 44 & 132 & -88 \\
\hline 134 & Zimbabwe & 43 & 133 & -90 \\
\hline 135 & Cameron & 41 & 135 & -94 \\
\hline 136 & Tajikistan & 39 & 134 & -95 \\
\hline 137 & Lao People's Dem. Rep. & 40 & 136 & -96 \\
\hline 138 & Bhutan & 39 & 136 & -97 \\
\hline 139 & Comoros & 38 & 137 & -99 \\
\hline 140 & Sudan & 37 & 138 & -101 \\
\hline 141 & Pakistan & 35 & 139 & -104 \\
\hline 141 & Mauritanai & 36 & 140 & -104 \\
\hline 143 & Bangladesh & 34 & 142 & -108 \\
\hline 144 & Djibouti & 33 & 143 & -110 \\
\hline 145 & Togo & 32 & 144 & -112 \\
\hline 146 & Uganda & 31 & 145 & -114 \\
\hline 147 & Myanmar & 30 & 146 & -116 \\
\hline 148 & Haiti & 29 & 147 & -118 \\
\hline 149 & Nepal & 28 & 148 & -120 \\
\hline 150 & Guinea & 27 & 148 & -121 \\
\hline 151 & Gambia & 26 & 150 & -124 \\
\hline 152 & Kenya & 25 & 151 & -126 \\
\hline 153 & Congo & 24 & 152 & -128 \\
\hline 154 & Angola & 22 & 152 & -130 \\
\hline 155 & Senegal & 22 & 154 & -132 \\
\hline 156 & Rwanda & 21 & 155 & -134 \\
\hline 157 & Côte d'Ivoire & 20 & 156 & -136 \\
\hline 158 & Nigeria & 19 & 157 & -138 \\
\hline 159 & Yemen & 18 & 158 & -140 \\
\hline 160 & Benin & 17 & 159 & -142 \\
\hline 161 & Madagascar & 16 & 160 & -144 \\
\hline 162 & Eritrea & 15 & 161 & -146 \\
\hline 163 & Central African Republic & 14 & 162 & -148 \\
\hline 164 & Chad & 13 & 163 & -150 \\
\hline 165 & Zambia & 12 & 163 & -151 \\
\hline 166 & Mozambique & 11 & 165 & -154 \\
\hline 167 & Tanzania, U. Rep. of & 10 & 166 & -156 \\
\hline 168 & Timor-Leste & 9 & 167 & -158 \\
\hline 169 & Malawi & 8 & 168 & -160 \\
\hline 170 & Ethiopia & 7 & 169 & -162 \\
\hline 171 & Congo, Dem. Rep. of the & 6 & 170 & -164 \\
\hline 172 & Burundi & 4 & 169 & -165 \\
\hline 173 & Guinea-Bissau & 5 & 171 & -166 \\
\hline
\end{tabular}




\begin{tabular}{lllll}
\hline Rank & Country & $\begin{array}{l}\text { Number } \\
\text { dominated } \\
\text { by country }\end{array}$ & $\begin{array}{l}\text { Number } \\
\text { dominating } \\
\text { country }\end{array}$ & $\begin{array}{l}\text { Net } \\
\text { dominance }\end{array}$ \\
\hline 174 & Mali & 3 & 173 & -170 \\
175 & Burkina Faso & 2 & 174 & -172 \\
176 & Sierra Leone & 1 & 175 & -174 \\
177 & Niger & 0 & 176 & -176 \\
\hline
\end{tabular}

\section{References}

1. Anand, S., Sen, A.: The income component of the human development index. J. Hum. Dev. 1, 83-106 (2000)

2. Booysen, F.: An overview and evaluation of composite indices of development. Soc. Indic. Res. 59, 115-151 (2002)

3. Chakravarty, S.R.: A generalized human development index. Rev. Dev. Econ. 7, 99-114 (2003)

4. Chatterjee, S.K.: Measurement of human development: an alternative approach. J. Hum. Dev. 6, 31-53 (2005)

5. Cherchye, L., Moesen W., Van Puyenbroeck T.: Legitimately diverse, yet comparable: on synthesising social inclusion performance in the EU. J. Common Mark. Stud. 42, 919-955 (2004)

6. Dar, H.A.: On making human development more humane. Int. J. Soc. Econ. 31, 1071-1088 (2004)

7. Despotis, D.K.: A reassessment of the human development index via data envelopment analysis. Int. J. Soc. Econ. 56, 969-980 (2005)

8. Dowrick, S., Dunlop, Y., Quiggin, J.: Social indicators and comparisons of living standards. J. Dev. Econ. 70, 501-529 (2003)

9. Fleurbaey, M., Hagneré, C., Trannoy, A.: Welfare comparisons with bounded equivalence scales. J. Econ. Theory 110, 309-336 (2003)

10. Fukada-Parr, S.: Indicators of human development and human rights - overlaps, differences and what about the human development index? Stat. J. U.N. 18, 239-248 (2001)

11. Fukada-Parr, S., Shiva Kumar, A.K.: Readings in Human Development. Oxford University Press, Oxford (2003)

12. Klasen, S., Bardhan, K.: UNDP's gender-related indices: a critical review. World Dev. 27, 985-1010 (1999)

13. Lind, N.: Values reflected in the human development index. Soc. Indic. Res. 66, 283-293 (2004)

14. Luchters, G., Menkhoff, L.: Chaotic signals from HDI measurement. Appl. Econ. Lett. 7, 267-270 (2000)

15. Maasoumi, E., Nickelsburg, G.: Multivariate measures of well-being and an analysis of inequality in the Michigan data. J. Bus. Econ. Stat. 6, 327-334 (1988)

16. Mahlberg, B., Obersteiner, M.: Remeasuring the HDI by data envelopment analysis. International Institute for Applied Systems Analysis Interim Report 01-069 (2001)

17. Mazumdar, K.: A new approach to human development index. Rev. Soc. Econ. 61, 535-549 (2003)

18. Nardo M., Saisana M., Saltelli A., Tarantola S., Hoffman A., Giovannini E.: Handbook on Constructing Composite Indicators: Methodology and User's Guide. OECD Statistics Working Paper (JT00188147) (2005)

19. Noorbakhsh, F.: A modified human development index. World Dev. 26, 517-528 (1998)

20. Panigrahi R., Sivramkrishna, S.: An adjusted human development index: robust country rankings with respect to the choice of fixed maximum and minimum indicator values. J. Hum. Dev. 3(2), 301-311 (2002)

21. Sagar, A., Najam, A.: The human development index: a critical review. Ecol. Econ. 25, 249-264 (1998)

22. Saisana, M., Saltelli, A., Tarantola, S.: Uncertainty and sensitivity analysis as tools for the quality assessment of composite indicators. J. R. Stat. Soc., Ser. A 168, 1-17 (2005)

23. United Nations Development Programme (1990-2004) Human development reports. http://www.undp.org. 